\title{
Study and Verification of a Physical Simulation System for Formation Pressure Testing while Drilling
}

\author{
Tianshou Ma $\mathbb{D}^{1,2}$ Nian Peng, ${ }^{1}$ Ping Chen $\mathbb{D}^{1},{ }^{1}$ Chunhe Yang, ${ }^{2}$ Xingming Wang $\mathbb{D},{ }^{1}$ \\ and Xiong $\mathrm{Han}^{3}$ \\ ${ }^{1}$ State Key Laboratory of Oil \& Gas Reservoir Geology and Exploitation, Southwest Petroleum University, Chengdu, \\ Sichuan 610500, China \\ ${ }^{2}$ State Key Laboratory of Geomechanics and Geotechnical Engineering, Institute of Rock and Soil Mechanics, Chinese Academy of \\ Sciences (CAS), Wuhan, Hubei 430071, China \\ ${ }^{3}$ Drilling and Production Engineering Technology Research Institute (CCDC), Guanghan, Sichuan 618300, China
}

Correspondence should be addressed to Tianshou Ma; matianshou@126.com

Received 30 March 2018; Revised 10 June 2018; Accepted 28 June 2018; Published 19 August 2018

Academic Editor: Fangtian Wang

Copyright (c) 2018 Tianshou Ma et al. This is an open access article distributed under the Creative Commons Attribution License, which permits unrestricted use, distribution, and reproduction in any medium, provided the original work is properly cited.

Based on a brief overview on the determination methods of formation pressure and their features, the major principle of formation pressure testing while drilling (FPTWD) and existing physical simulation systems was introduced, and the deficiency of the existing physical simulation systems was also discussed. A laboratory high-precision physical simulation system was therefore developed to simulate the downhole testing environment and testing process of FPTWD. The present experimental system was designed to endure pressures up to $20,000 \mathrm{psi}$, and the relative control accuracy of pressure is approximately $0.02 \%$ FS. Two kinds of man-made specimens with the permeability of $10-110 \mathrm{mD}$ were used to test the pressure response and to verify the present physical simulation system. The debugging results indicated that the variation amplitude under the stable condition is approximately $0.07 \mathrm{psi}, 0.08 \mathrm{psi}, 0.11 \mathrm{psi}$, and $0.11 \mathrm{kN}$ for the annular pressure, pore pressure, confining pressure, and thrust force, respectively. Thus, the high control accuracy is approximately $\pm 1.0 \mathrm{psi}$ under the stable conditions. The experimental results indicated that the pressure drawdown declines rapidly in the stage of withdrawing formation fluids and then recovers slowly. The pressure drop amplitude also decreases with permeability, while the pressure buildup amplitude increases with permeability. The tendency of pressure change is nearly the same for both the present and the previous systems, and the pressure curve of the present system is much smoother and better than that of the previous system. The relative error of explaining formation pressure is less than $1 \%$ and $4 \%$ for the present and the previous systems, respectively. In addition, this physical simulation system has important applications to verify the interpretation model, to analyze pressure response recorded by FPTWD tools, to test the capability and design of FPTWD tools, and to calibrate the formation pressure, formation parameters, and instrument factors.

\section{Introduction}

Pore pressure, also known as the formation pore pressure or the formation pressure, refers to the fluid (oil, gas, and water) pressures in the pore spaces of porous formations $[1,2]$. In general, the normal pore pressure increases with depth at a constant gradient (i.e., the hydrostatic pressure gradient); if the pore pressure is lower or higher than the hydrostatic pressure or normal formation pressure, it is an abnormal pore pressure $[3,4]$. When the pore pressure is higher than the normal pore pressure, it is overpressure or abnormal high pore pressure; while when the pore pressure is lower than the normal pore pressure, it is underpressure or subnormal pore pressure $[5,6]$. The abnormal pore pressure has so many impacts on the exploration, exploitation, and utilization activities of deep earth geo-energy and geo-resources, such as the petroleum drilling, scientific drilling, petroleum exploitation, geothermal exploitation, $\mathrm{CO}_{2}$ geological sequestration, and nuclear waste disposal [7-11].

In the process of petroleum drilling and scientific drilling, pore pressure is one of the most important parameters for the drilling plan; it can be used to optimize the drilling fluid 
density, wellbore configuration, and pressure control equipment. If the abnormal pore pressure cannot be accurately predicted, some very complex down-hole incidents, such as fluid influx, gas kick, overflow, blowout, and mud loss, can occur and even occur the out-of-control blowout and lost circulation in a severe case, which obviously increase the drilling risk, cycle, and costs $[5,6]$. In the process of petroleum exploitation, pore pressure is an important basic parameter for oil and gas development; it can be used to characterize the type of reservoir, estimate geological reserves, determine the energy of oil and gas reservoir, and conduct the prediction of production performance, which determines the formation fluid properties, the development mode, and the ultimate recovery [12]. In the process of geothermal exploitation, pore pressure has a significant impact on the dynamic production performance and geothermal resource recovery $[13,14]$. In the process of $\mathrm{CO}_{2}$ geological sequestration and nuclear waste disposal, pore pressure affects the injection capacity of $\mathrm{CO}_{2}$ or nuclear waste, and it also has a significant impact on the long-term storage capacity $[15,16]$. Thus, it is very important to determine the formation pressure for petroleum drilling, scientific drilling, petroleum exploitation, geothermal exploitation, $\mathrm{CO}_{2}$ geological sequestration, and nuclear waste disposal.

Currently, there are five kinds of conventional methods that can be used to determine formation pressure, such as the seismic method, $d_{c}$-exponent method, well logging method, drill stem test (DST), and wire-line formation test (WFT) $[5,6]$. However, these methods are usually featured by low precision and poor real time, which makes accurately detecting formation pressure in real time become very difficult. In order to overcome the problems mentioned above, on the basis of traditional WFT and measurement while drilling technologies, the concept of formation pressure testing while drilling (FPTWD) was put forward. The FPTWD tester is installed in the bottom-hole assembly (BHA), and the formation pressure is tested in the process of a short pause under drilling operations $[3,4]$. Therefore, the detection of formation pressure becomes more accurate and real time. Due to the great advantages of FPTWD tester, PETROCHINA, SINOPEC, and CNOOC of China also began to conduct research and development of FPTWD tools. But there are still no mature FPTWD products in China; the main reason is that there is a lack of a verification method for the FPTWD tool.

Thus, the aim of the present paper is to overview the determination methods and the major principle of formation pressure testing and to introduce a new physical simulation system for FPTWD and its application. In Section 2 , the conventional determination methods of formation pressure and their features were introduced, the major principle of FPTWD and existing physical simulation systems for FPTWD was reviewed, and the deficiency of the existing physical simulation systems was also discussed. In Section 3, a new kind of physical simulation system for FPTWD was designed; the key parts of this physical simulation system, such as the sample size, core holder, control system, and main operating procedures, had been introduced. In Section 4, two typical experiments were introduced to verify the present physical simulation system; the debugging results, testing results, and discussions were also discussed.

\section{Overview of the Determination of Formation Pressure}

2.1. Conventional Methods for the Determination of Formation Pressure. In order to use pore pressure to guide the exploration, exploitation, and utilization activities of deep earth geo-energy and geo-resources, many scholars had therefore proposed the prediction or detection method of pore pressure. The fundamental theory of pore pressure prediction is based on Terzaghi's and Biot's effective stress law, which indicates that the pore pressure is a function of total stress and effective stress [5]. In other words, when the total stress and effective stress are obtained, the pore pressure can be determined by using Terzaghi's and Biot's effective stress law. In which, the total stress can be easily determined from the overburden pressure of formations, while the determination of effective stress is generally more difficult. In 1965, Hottmann and Johnson conducted the earliest study on pore pressure prediction for shale formations [17]; their discovery became known as the normal compaction theory. From then on, many prediction methods of pore pressure were presented based on resistivity, sonic transit time, natural potential, seismic wave velocity, and other well logging data [5].

According to the fundamental theory, the conventional prediction method for pore pressure can be classified into two main categories: (1) prediction method based on normal compaction trend (NCT): the determination of the NCT is critically important; the most commonly used methods include the equivalent depth method [18], Eaton's method $[19,20]$, and modified Eaton's method [21]; the logging data used include resistivity, sonic transit time, and natural potential, and (2) prediction method based on effective stress theory: it is unnecessary to determine the NCT; the most common used methods include Bowers' method [22], Miller's method [5], Tau method [23], Zhang's method [24], and Eberhart-Phillips' method [25]; these methods mainly be determined by using acoustic logging data and other well logging data. Due to the compaction theory which is suitable for mudstone or shale formation, thus, these methods can be used to predict pore pressure for mudstone or shale formation. Currently, the difficulty is to predict the pore pressure for carbonate formations [26]. According to the obtaining order, the conventional prediction or detection method for pore pressure can be classified into three categories:

(1) Predrill pore pressure prediction: pore pressure can be predicted by extracting the seismic wave velocity from geophysical exploration data, but seismic data often lack the spatial resolution needed for accurate pore pressure prediction [1]. Thus, this method is usually suitable for pore pressure prediction in new exploration areas or new exploration wells. 

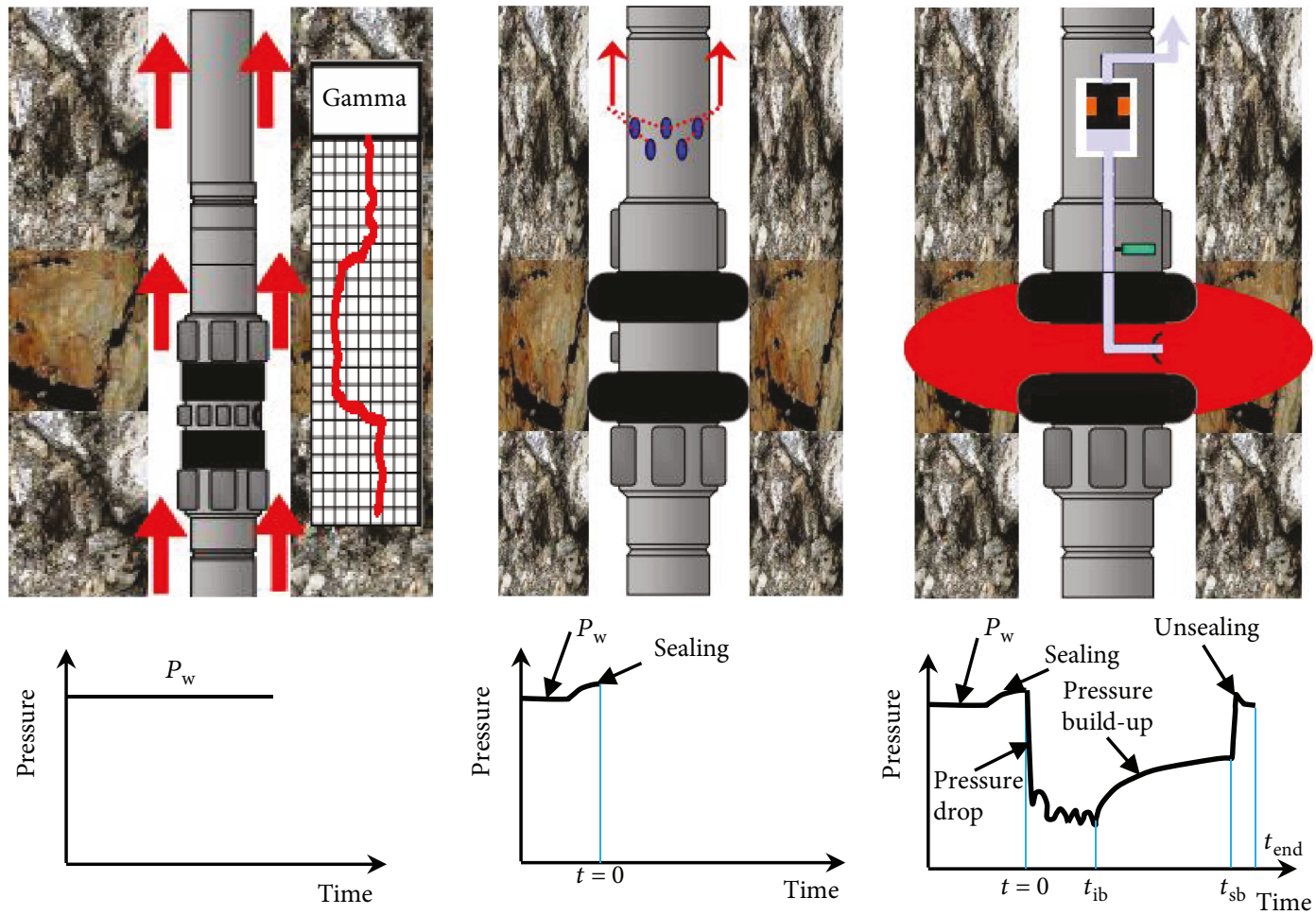

(a) Seeking pattern

(b) Testing pattern

(c) Testing pattern

FIgure 1: Testing principle of Drilling Formation Tester (DFT) (reproduced from [30]). (a) Seeking pattern (location by using gamma logging). (b) Testing pattern (setting packer to seal). (c) Testing pattern (pressure drop and buildup testing).

(2) Pore pressure detection during drilling: pore pressure can be detected by using drilling parameters, the theoretical basis is still the normal compaction theory, where the rate of penetration (ROP) data is used to determine NCT, and the most commonly used methods include the $d_{c}$-exponent method and sigma exponent method $[5,6]$, but the detection precision is very poor.

(3) Postdrill pore pressure prediction or detection: for postdrill pore pressure prediction, it mainly refers to the logging-based prediction methods; both the normal compaction theory and the effective stress theory can be used; and resistivity, sonic transit time, natural potential, and other well logging data are suitable. For postdrill pore pressure detection, the main methods include DST and WFT [27-29]; these two methods can test the pore pressure accurately, but the DST and WFT are featured by time-consuming, inefficiency, and high cost. In addition, the WFT tool is usually difficult to run into the highly deviated well and horizontal well, and there is a risk of sticking pipe, slacking off, and fishing during formation pressure testing $[3,4]$.

2.2. Formation Pressure Testing while Drilling (FPTWD). In order to improve the detection precision of pore pressure, some new requirements are raised in the application of WFT. In the middle and later periods of the 1990s, on the basis of traditional WFT and measurement while drilling technologies, the foreign oilfield technology service companies put forward the concept of formation pressure testing while drilling (FPTWD) to overcome the disadvantages of DST and WFT. The probe-type FPTWD tester is installed in the bottom-hole assembly (BHA), and the formation pressure is tested in the process of a short pause under drilling operations.

In 1999, Pathfinder Company developed the first FPTWD tester, that is, the Drilling Formation Tester (DFT), where the structure of double packers was designed, as shown in Figure 1; the main processes of DFT testing are as follows [30]: (1) locate the down-hole position of DFT by using gamma logging data; (2) send a starting command to activate the down-hole DFT and to set the packer; (3) let the down-hole DFT launch the test sequence, including pressure drop, pressure buildup, and unsealing processes. However, due to the friction effect between the rubber packer and the borehole wall, the packers are easy to damage during the rotation of the drill string; consequently, these two packers cannot seal the borehole annulus and the whole test failed.

In 2002, Halliburton Company developed a probe-type FPTWD tester, the Geo-Tap system, to solve the problem mentioned above [31]. Figure 2(a) shows the major components of the typical probe-type FPTWD tester, Figure 2(b) shows the main workflow of the FPTWD tester, and Figure 2(c) shows the pressure response curve of the FPTWD tester. As shown in Figures 2(a) and 2(b), the main processes 


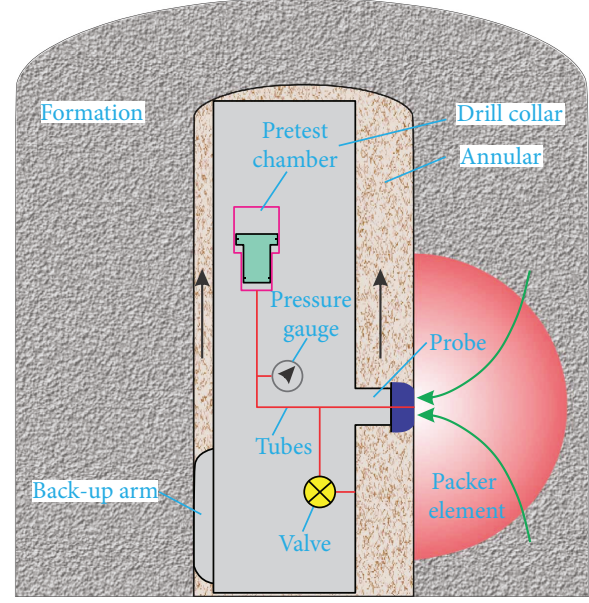

(a)

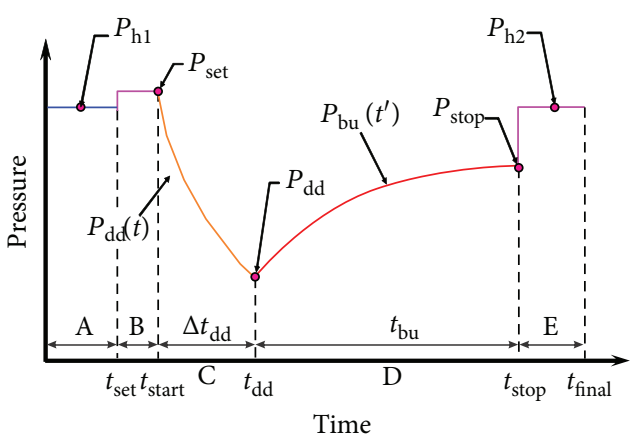

(c)

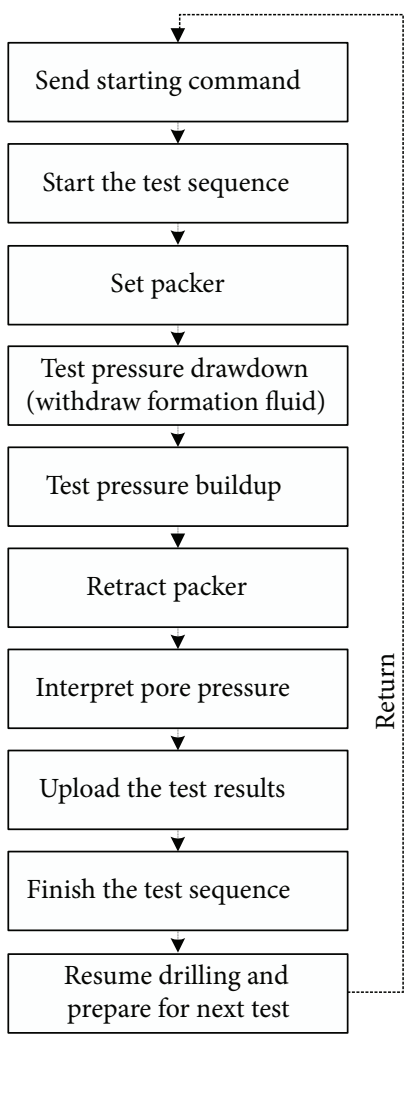

(b)

FIGURE 2: Testing principle of a typical probe-type FPTWD tester. (a) Major components of the typical FPTWD tester (reproduced from [4]). (b) Testing workflow (reproduced from [4]). (c) Testing pressure response curve (reproduced from [32-34]).

of FPTWD testing are as follows: (1) lift or lower the drill string to locate the down-hole position of the FPTWD tester; (2) send a starting command to activate the down-hole FPTWD tester; (3) let the down-hole FPTWD tester launch the test sequence of formation pressure testing; as shown in Figure 2(c), the test sequence mainly includes five stages $[3,4]$ : (A) pretest stage, (B) set packer stage, (C) pressure drawdown stage, (D) pressure buildup stage, and (E) posttest stage; (4) after testing the pressure response, the down-hole FPTWD tester processes the pressure response curve, then the processing results to the surface were uploaded, and the test sequence was finished; (5) once the down-hole data upload is completed, the test sequence ends automatically, and then the drilling operations can be continued.

From then on, various oilfield technology service companies have also developed several kinds of probetype FPTWD testers: Baker-Hughes Company developed the Tes-Trak system, Schlumberger Company developed the Stetho-Scope system, and Weatherford Company developed the Compact-MFT system [35]. The probe-type FPTWD tester is installed in the bottom-hole assembly (BHA), and the formation pressure is tested in the process of a short pause under drilling operations. The FPTWD tester starts the formation pressure testing for a short time as long as wells have been drilled; that is, the mud invasion has just started during the procedure, so that the measured pore pressure is more accurate $[3,4]$. Furthermore, because the FPTWD tester can determine the pore pressure without removing the drill string from the borehole, it can overcome the disadvantages of DST and WFT, the FPTWD is featured by real-time, high-accuracy, high-efficiency detection of pore pressure, and the difficulty of WFT run into the highly deviated well and horizontal well is also solved.

Due to the great advantages of the FPTWD tester, PETROCHINA, SINOPEC, and CNOOC of China also began to organize research and development of FPTWD tools: Chuan and coauthors, working at the Southwest Petroleum University, developed a prototype tool of the probe-type FPTWD [35]; Zhao and coauthors, working at the Daqing Drilling Engineering Company of PetroChina, developed an SDC-I type of the FPTWD tool and conducted the field test in 6 wells [36]; Zheng and coauthors, working at the Research Institute of Petroleum Engineering of SINOPEC, developed a prototype tool of the probe-type FPTWD [37]. On the whole, these studies had made a great progress, but there are still no mature FPTWD products; the main reason is that there is a lack of a verification method for the FPTWD tool, and the results are as follows: (1) the reasonable design parameters of FPTWD tools are not very clear, such as the suction scheme, suction rate, suction volume, and push force of the probe; (2) the theoretical model of pressure response and data processing method is very difficult to validate; (3) the 
performance of the FPTWD tool is very difficult to test. Thus, in order to speed up the process of research and development for FPTWD tools, it is necessary to develop a physical simulation system for formation pressure testing while drilling. Therefore, the present paper aimed at developing a high-precision physical simulation system for the FPTWD tester and conducting the application of this physical simulation system.

2.3. Existing Physical Simulation Systems for FPTWD. In fact, the process of formation pressure testing is actually a fluid seepage process in pore spaces of porous formations. The most important stages are mainly the pressure drawdown stage and pressure buildup stage. The formation pressure, time constant, and buildup magnitude can be determined by multiple linear regression of the buildup pressure curve $[30,31,35]$. Once we obtained the time constant and buildup magnitude, the formation fluidity and fluid compression coefficient also can be determined, where the fluidity refers to the ratio of the permeability to viscosity. In addition, some instrument factors, such as the probe geometric shape factor, flowline volume, and flow factor of drawdown pressure, need to be calibrated before the FPTWD tool is used. If these instrument factors did not calibrate accurately, the calculation results of the FPTWD tool are not credible.

The physical simulation of formation pressure testing is a very important aspect to achieve the objective that was mentioned above, but only very little laboratory work had been published. In 1994, Desbrandes and Xu [38] conducted the pressure transient test for the WFT system, and the influence of the actual mud system or mud cake was involved; however, the experimental apparatus was not introduced, and these tests were conducted in only a few cases and with very low formation pressures less than 600 psi.

In 1995, Ramakrishnan et al. [39] designed an experimental apparatus to investigate the permeability in hemispherical flow with application to formation testers; this experimental apparatus can flow fluids through a probe under isotropic confining stresses. It mainly consists of the pressure vessel, the rubber jacket, the floating piston, probe-packer assembly, two pumps, several valves, several sensors, the control system, and the computer. The radius of the specimen was designed as twice the length to test the anisotropic permeability. A number of synthetic and natural rocks were used to conduct pressure measurements on confining pressure, probe size, flow rate, and flow direction for WFT conditions, but they did not test the pressure response of formation testing.

In 2004, Lee et al. [40] designed an experimental apparatus to analyze pressure transients recorded by the Geo-Tap FPTWD tool; the experimental apparatus mainly consists of the core holder, three cylinders, three pumps, the drawdown piston, two transducers, three solenoids, and an electrical control and visualization system. Although the antipressure ability of this experimental apparatus can reach 6000 psi and they reported $\sim 180$ experiments were conducted, only five representative cases were published, and these five experiments were performed with very high permeabilities higher than $982 \mathrm{mD}(982 \mathrm{mD}, 1946 \mathrm{mD}$, and $3649 \mathrm{mD}$ ) and medium formation pressures less than 2000 psi (500 psi, 1500 psi, and 2000 psi).

In 2014, Ma and coauthors [3,4] also developed an experimental apparatus for the FPTWD system. It mainly consists of the work platform, the core gripper, the push action cylinder, the pretest chamber, three pressurizers, three pumps, seven valves, the main control board, and the computer. The main performance indicators are listed as follows: specimen diameter is $100 \mathrm{~mm}$, specimen length is 50 $200 \mathrm{~mm}$ (adjustable), confining pressure is $0-10,000 \mathrm{psi}$ with a precision of $\pm 0.5 \%$, formation pressure is $0-10,000 \mathrm{psi}$ with a precision of $\pm 0.5 \%$, annular pressure is $0-10,000 \mathrm{psi}$ with a precision of $\pm 0.5 \%$, withdrawn volume is $0-25 \mathrm{ml}$ with a precision of $\pm 0.1 \%$, and drawdown flow rate is $0-5 \mathrm{ml} / \mathrm{s}$ with a precision of $\pm 0.1 \%$. They conducted a large number of experiments to verify the validity of the analytical model, to analyze pressure response recorded by FPTWD tools, and to test the capability and design of FPTWD tools. There are seven representative cases published, and these experiments were performed with medium-low permeabilities lower than $120 \mathrm{mD}(1.14-110.25 \mathrm{mD})$ and medium-high formation pressures less than $3000 \mathrm{psi}$ (2393-2973 psi).

The physical simulation system can be used to verify the interpretation model and to analyze pressure response recorded by FPTWD tools. It also can be used to calibrate the instrument factors, the pore pressure, formation fluidity, and fluid compression coefficient. Currently, only three kinds of experimental apparatuses have been reported, and only very few experiments associated with the pressure response of FPTWD have been published. This experimental apparatus was not used to calibrate the FPTWD tools, maybe because the precision requirement of the physical simulation system is very high, and these systems have no enough precision. Due to these instrument factors, formation fluidity and fluid compression coefficient are very sensitive to the pressure; the precision requirement of the physical simulation system is very high. In general, the resolution of the pressure sensor in the FPTWD tool is approximately $1.0 \mathrm{psi}$; thus, the control accuracy of the physical simulation system should be as close to $1.0 \mathrm{psi}$ as possible. The precision performances of existing physical simulation systems were reported rarely; only $\mathrm{Ma}$ and coauthors $[3,4]$ provided the precision performances, but its precision of all pressure is $\pm 0.5 \%$ with a measurement range of $0-10,000 \mathrm{psi}$; that is, the absolute precision of full range is approximately $\pm 50 \mathrm{psi}$, and it is not enough to calibrate the FPTWD tools. Therefore, it is necessary to develop a high precision physical simulation system to investigate the pressure response recorded by FPTWD tools, to verify the validity of the analytical model, and to calibrate the instrument factors, the pore pressure, formation fluidity, and fluid compression coefficient.

\section{Study of the Physical Simulation System}

3.1. System Design. In view of the need for testing the pressure response recorded by FPTWD tools, testing the capability and design of FPTWD tools, verifying the interpretation 


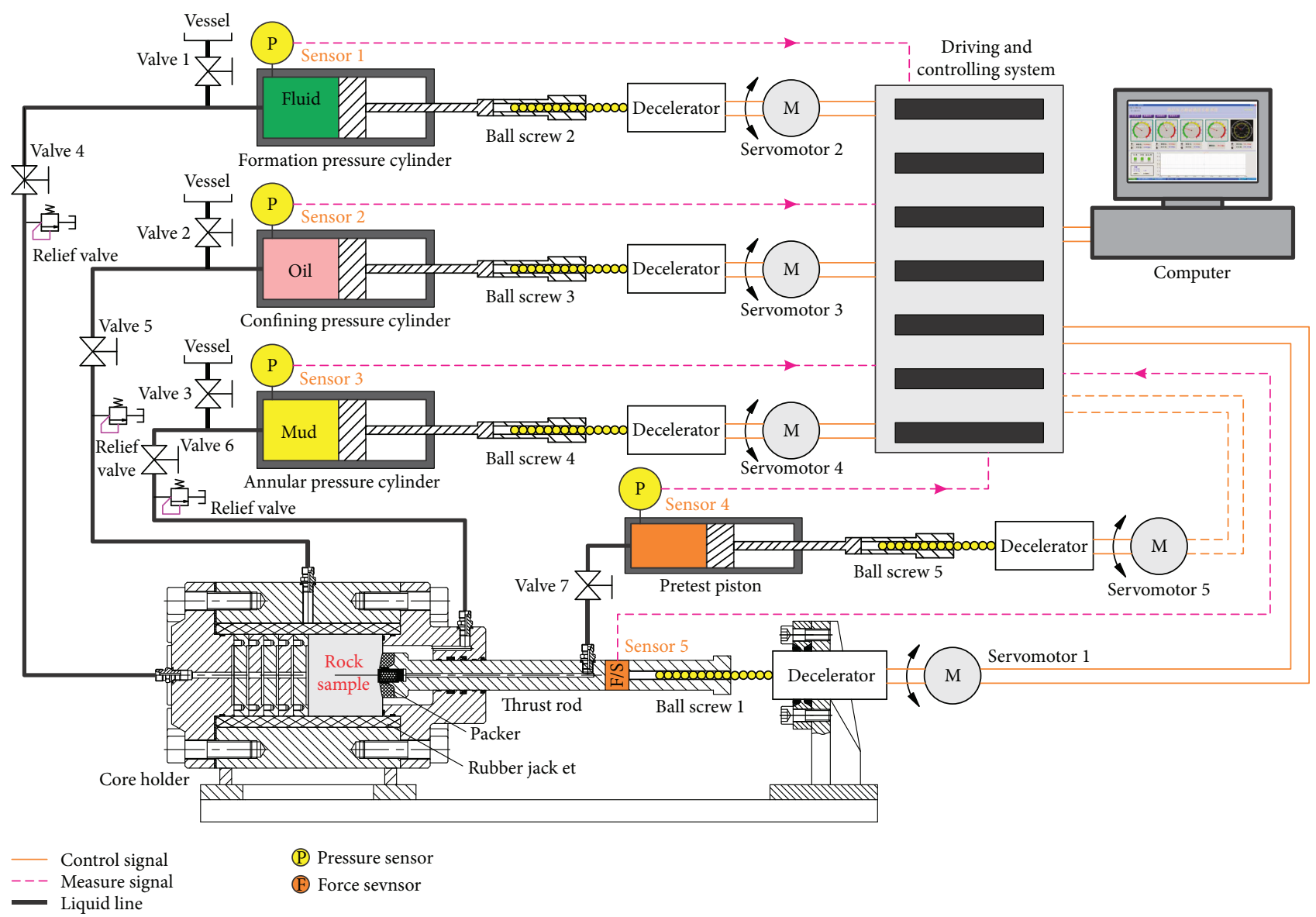

FIgURE 3: Schematic of the physical simulation system for FPTWD.

model, and calibrating the instrument factors and FPTWD tools, a physical simulation system for FPTWD was designed that could simulate the action of the FPTWD tool under simulated wellbore conditions. According to the testing principle of FPTWD tools, the schematic of the physical simulation system is shown in Figure 3. The physical simulation system is composed of the foundation, the core holder, the packer, the thrust rod, the pretest piston, five servomotors, five decelerators, five ball screws, three cylinders, three vessels, seven break valves, three relief valves, five sensors, several controlling and measuring lines, several liquid lines, the driving and controlling system, and the computer. The present physical simulation system can simulate the testing environment, such as the formation pressure, the confining pressure, the annulus pressure, and the packer setting.

\subsection{Sample Size Determination}

3.2.1. Sample Diameter. The key to conduct the physical simulation for FPTWD is the determination of the representative sample such as shape and size. Although the specimen diameter of $160 \mathrm{~mm}$ and specimen length of $50-200 \mathrm{~mm}$ (adjustable) are given in Section 3.1, we should discuss how to determine the sample size. Thus, we analyzed the relationship of pressure distribution near the borehole wall. Considering a typical seepage problem of FPTWD, as shown in
Figure 2(a), the analytical model of the pressure response equation can be expressed as

$$
\frac{1}{r^{2}} \frac{\partial}{\partial r}\left(r^{2} \frac{\partial P}{\partial r}\right)=\frac{1}{\eta} \frac{\partial P}{\partial t}
$$

where pressure transmitting coefficient $\eta$ is given as

$$
\eta=\sqrt{\frac{k_{\mathrm{f}}}{\phi_{0} \mu C_{\mathrm{t}}}} .
$$

The boundary conditions and initial conditions are given as follows:

$$
\begin{aligned}
\left.\frac{\partial P}{\partial r}\right|_{r=r_{\mathrm{w}}} & = \begin{cases}\frac{q \mu}{2 \pi r_{\mathrm{p}}^{2} k_{\mathrm{f}}}, & \text { solution domain } \Gamma_{1}, \\
0, & \text { solution domain } \Gamma_{2},\end{cases} \\
P(r \rightarrow \infty, t) & =P_{\mathrm{i}}, \\
P(r, t=0) & =P_{\mathrm{i}},
\end{aligned}
$$

where $r$ is the radial distance (m), $\eta$ is the pressure transmitting coefficient, $\phi_{0}$ is the porosity (\%), $\mu$ is the fluid viscosity (cp), $P$ is the pressure (psi), $k_{\mathrm{f}}$ is the formation spherical permeability (md), $C_{\mathrm{t}}$ is the comprehensive compression coefficient $\left(\mathrm{psi}^{-1}\right), t$ is the time $(\mathrm{s}), r_{\mathrm{w}}$ is the wellbore radius $(\mathrm{cm})$, 


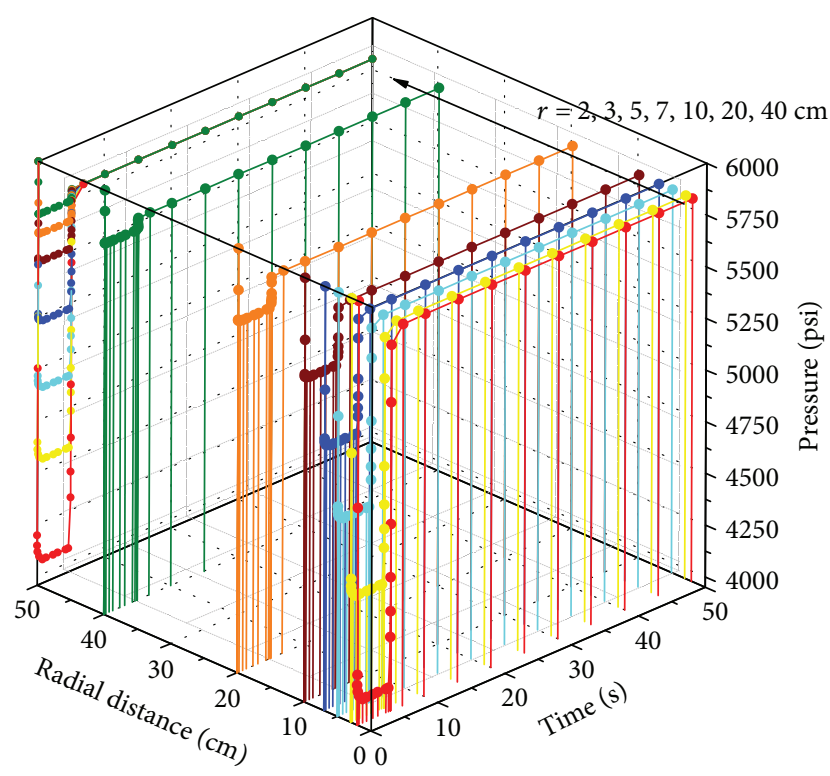

FIgURE 4: Pressure distribution versus time and radial distance.

$r_{\mathrm{p}}$ is the probe radius $(\mathrm{cm}), q$ is the withdrawn flow rate of fluid $(\mathrm{cc} / \mathrm{s})$, and $P_{\mathrm{i}}$ is the initial pore pressure (psi).

According to (1), (2), and (3), we can solve the analytical solution by using the Laplace transformation, and the analytical solution of the ideal pressure response equation can be given as

$$
P=P_{\mathrm{i}}-\frac{q \mu}{2 \pi k_{\mathrm{f}} r} \operatorname{erfc}\left(\frac{r}{2 \eta \sqrt{t}}\right) .
$$

Assume a typical wellbore condition which has the pore pressure of $5800 \mathrm{psi}$, wellbore pressure of $6000 \mathrm{psi}$, porosity of $10.0 \%$, permeability of $10 \mathrm{mD}$, fluid viscosity of $1 \mathrm{mPa} \cdot \mathrm{s}$, comprehensive compression coefficient of $2.07 \times 10^{-6} \mathrm{psi}^{-1}$, wellbore radius of $10.8 \mathrm{~cm}$, probe radius of $1.0 \mathrm{~cm}$, and withdrawn flow rate of $1 \mathrm{ml} / \mathrm{s}$. Using (4), if the withdrawn time is $5 \mathrm{~s}$, then the pressure distribution near the borehole wall is shown in Figure 4. It is very clearly found that the pressure drop mainly appears near the testing probe, the pressure drop is approximately $1608 \mathrm{psi}, 1158 \mathrm{psi}, 836 \mathrm{psi}, 536 \mathrm{psi}$, $268 \mathrm{psi}, 143 \mathrm{psi}$, and $53 \mathrm{psi}$ for a radial distance of $2 \mathrm{~cm}$, $3 \mathrm{~cm}, 5 \mathrm{~cm}, 7 \mathrm{~cm}, 10 \mathrm{~cm}, 20 \mathrm{~cm}$, and $40 \mathrm{~cm}$, respectively. When the radial distance is greater than $10 \mathrm{~cm}$, the pressure drop is less than $300 \mathrm{psi}$, and when the radial distance is greater than $20 \mathrm{~cm}$, the pressure drop is less than $150 \mathrm{psi}$; thus, when the radial distance reaches a limited value, the pressure drop must be small enough. In other words, the typical seepage problem of FPTWD can be regarded as the seepage problem with a finite boundary. Therefore, the physical simulation of FPTWD is reasonable and feasible. From this point of view, the reasonable ratio of supply boundary to probe should be higher than 10-20 for FPTWD. In general, the diameter of the probe is approximately $10 \mathrm{~mm}$, and the sample size is recommended larger than $100 \mathrm{~mm}$ in diameter.

3.2.2. Sample Length. As shown in Figure 5, the seepage process of FPTWD should be a hemispherical seepage problem.
Thus, we should investigate the controlling relationship between physical simulation and FPTWD testing. For the physical simulation provided in Figure 3, the pore pressure is applied at the right end of the sample, and the probe is applied at the center of the left end of the sample. Thus, the physical model of physical simulation is shown in Figure 5; the measured pressure is a reflection of both hemispherical and linear flows. In order to ensure the boundary effects do not affect the pressure testing and the flow characteristics are largely hemispherical, the following conditions are imposed [39]:

$$
\begin{aligned}
\frac{r_{\mathrm{p}}}{R} & \ll 1, \\
\frac{r_{\mathrm{p}}}{L} & \ll 1, \\
\frac{\Delta P_{1}}{\Delta P} & \ll 1,
\end{aligned}
$$

where $R$ is the sample radius $(\mathrm{cm}), L$ is the sample length (cm), $\triangle P_{1}$ is the pressure drop of the linear flow (psi/ $\mathrm{cm}$ ), and $\triangle P$ is the pressure drop of the hemispherical flow (psi/cm).

As shown in Figure 5, in cylindrical coordinates with the origin at the center of the left end of the sample and the $z$-axis coinciding with the axis of the sample, the equilibrium equation of pore fluid can be expressed as [39]

$$
\frac{\partial^{2} P}{\partial r^{2}}+\frac{1}{r} \frac{\partial P}{\partial r}+\frac{\partial^{2} P}{\partial z^{2}}=0 .
$$

The boundary conditions and initial conditions are given as follows:

$$
\begin{aligned}
& \int_{0}^{r_{\mathrm{p}}} \frac{\partial P}{\partial z} r d r=-\frac{q \mu}{2 \pi k_{\mathrm{f}}}, \quad r<r_{\mathrm{p}}, z=0, \\
&\left.\frac{\partial P}{\partial r}\right|_{r=R}=0, \\
& P(r, z=L, t)=P_{\mathrm{i}}, \\
& P(r, z=0, t=0)=P,
\end{aligned}
$$

where $r$ is the radial distance $(\mathrm{cm}), z$ is the $z$-axial distance $(\mathrm{cm}), L$ is the sample length $(\mathrm{cm})$, and $R$ is the sample radius (cm).

According to (6) and (7), we can solve the analytical solution of the ideal pressure drop.

$$
\Delta P=\frac{q \mu}{k_{\mathrm{f}}}\left[\frac{1}{4 r_{\mathrm{p}}}-\frac{\ln 2}{2 \pi L}+\frac{1}{\pi L} \sum_{n=1}^{\infty} \frac{K_{1}(n \pi R / 2 L)}{I_{1}(n \pi R / 2 L)}\right],
$$

where $K_{1}()$ and $I_{1}()$ are the Bessel functions.

In (8), the first term on the right belongs to the hemispherical flow term, while the second term on the right belongs to the linear flow term. Thus, according to the assumed conditions of (5), the linear flow term should satisfy the following condition: 

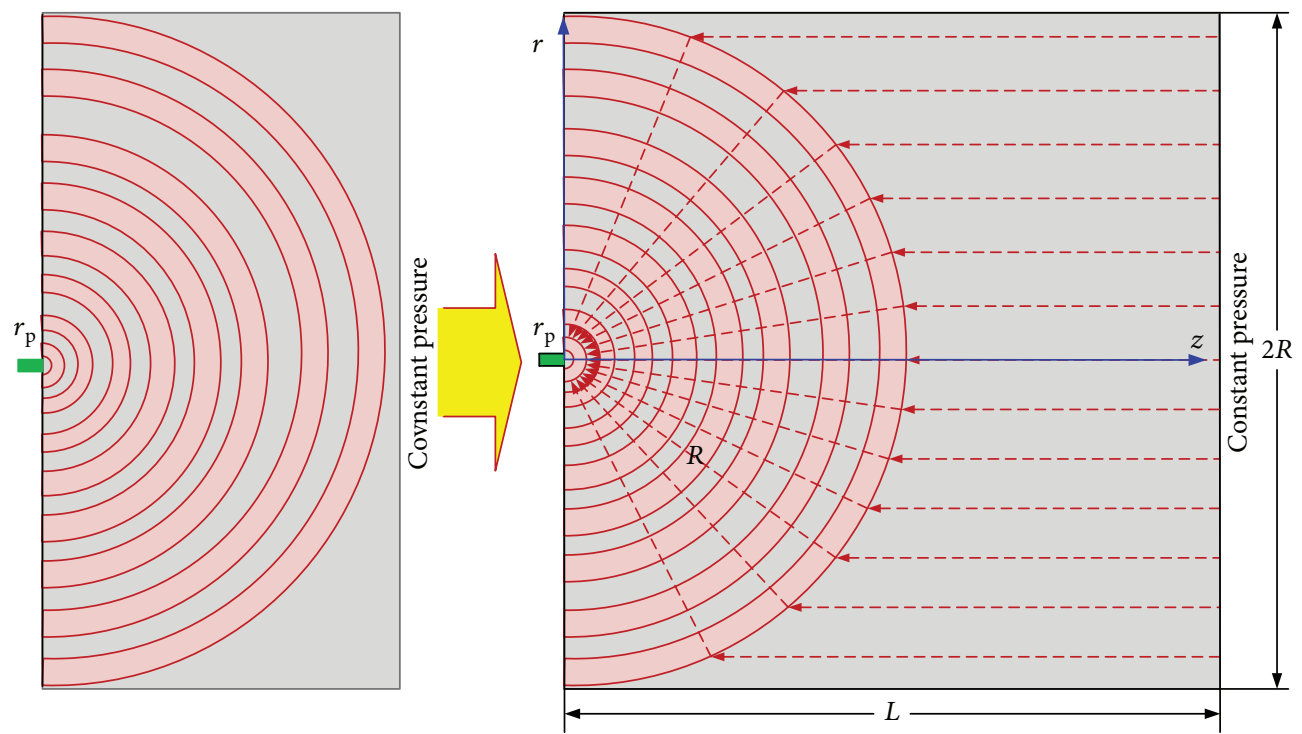

FIGURE 5: Streamlines in a finite physical simulation sample.

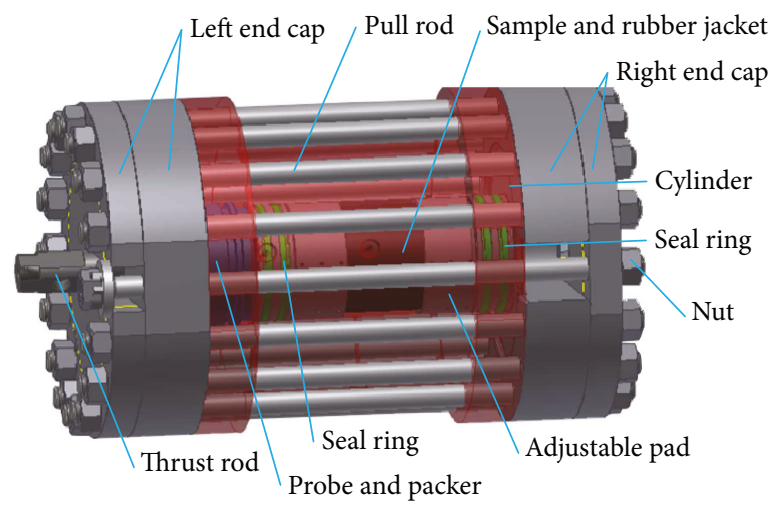

(a)

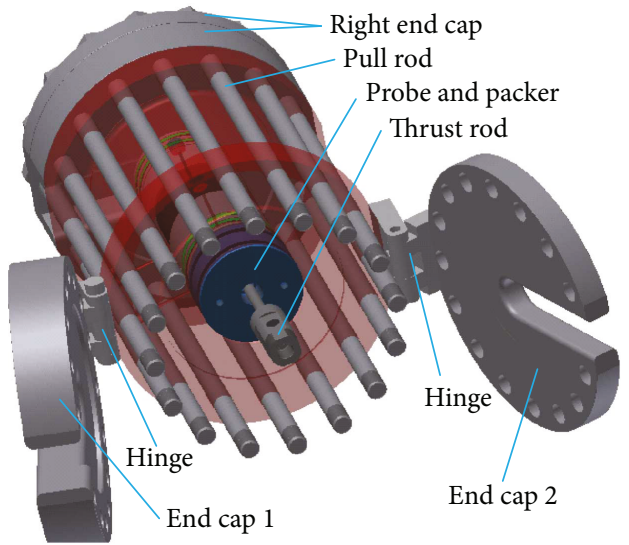

(b)

Figure 6: Configuration of the core holder. (a) Assembly drawing of the core holder. (b) Opening situation of the left end cap.

$$
-\frac{\ln 2}{2 \pi L}+\frac{1}{\pi L} \sum_{n=1}^{\infty} \frac{K_{1}(n \pi R / 2 L)}{I_{1}(n \pi R / 2 L)}=0 .
$$

Reduction (9), we can obtain

$$
R=\frac{\ln (2 \pi / \ln 2)}{\pi} L=0.7 L
$$

Equation (10) presents the relationship to determine the sample size. In general, the probe diameter is approximately $10 \mathrm{~mm}$; if the sample diameter is set as $100 \mathrm{~mm}$, then the length of the sample should be $72 \mathrm{~mm}$; if the sample diameter is set as $160 \mathrm{~mm}$, then the length of the sample should be $114 \mathrm{~mm}$.

On the basis of determination for sample diameter and length, considering the requirements of a larger probe, the sample size is recommended as $160 \mathrm{~mm}$ in diameter and 50-200 $\mathrm{mm}$ in length, and the length can be adjusted from
$50 \mathrm{~mm}$ to $200 \mathrm{~mm}$, so that the influence of sample size on physical simulation can be investigated.

3.3. Core Holder. In order to conduct experiments related to high pressure $(20,000 \mathrm{psi})$, the laboratory is configured with a high-pressure core holder which can concurrently bear the pore pressure, confining pressure, and wellbore pressure. The configuration of the core holder is shown in Figure 6; it is mainly composed of the cylinder, two end caps, adjustable pad, seal ring, thrust rod, rubber jacket, probe and packer, several pull rods, and several nuts. The maximum operating pressure is 20,000 psi that can satisfy the requirements of high-pressure physical simulation; thus, the axial force that is induced by the operating pressure exceeds $2800 \mathrm{kN}$. The configuration of the pull rod is suitable for tension, so the configuration of the pull rod is adapted to against the high operating pressure for the pore pressure, confining pressure, and wellbore pressure. The von Mises stress distribution in 


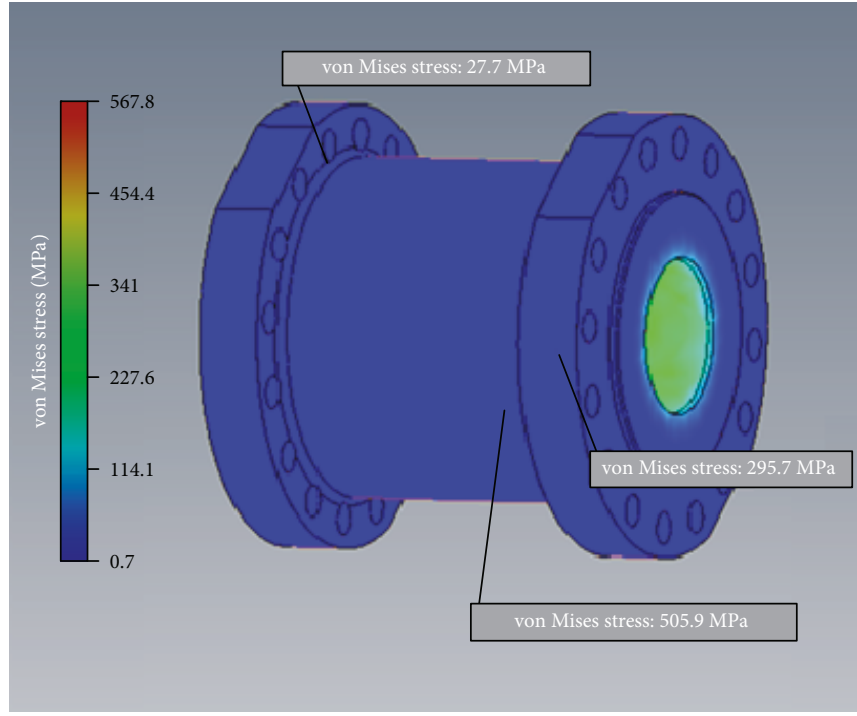

(a)

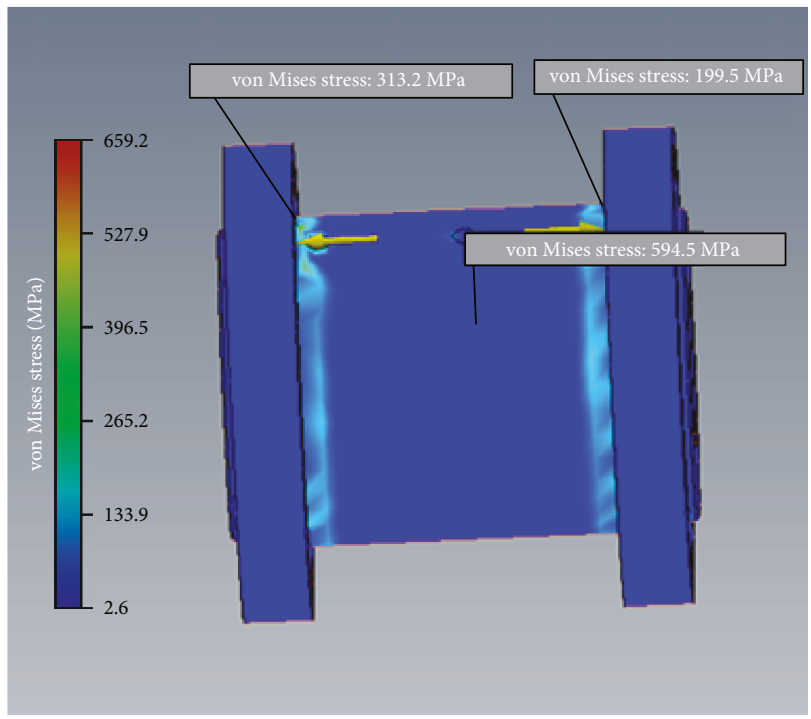

(b)

Figure 7: von Mises stress distribution in the cylinder. (a) Configuration of the pull rod. (b) Assembled configuration.

the cylinder is shown in Figure 7, the maximum stress occurs at the inner wall of the cylinder, but if the assembled configuration is used, the maximum stress occurs at the outer wall of the cylinder. Consequently, the cylinder does not bear the axial force that is induced by the operating pressure; it is beneficial to the safety of the high pressure vessel. The left and right end caps are composed of two end caps that are connected by hinge to enhance operability, because the end cap is very heavy. End cap 1 is inside and end cap 2 is outside, and the sealing is provided by cylinder, end cap 1, and seal ring, while end cap 2 just provides the effect of compaction by the pull rod and nut.

3.4. Control System. The difficulty of the control system is to achieve the high-precision control. In order to enhance the control precision of pressure, flow rate, and force, the high-precision servo control system was used, and the core components consist of the servo controller, synchronous motor, decelerator, and ball screw. According to the requirements of physical simulation, there are five closedloop control subsystems, such as formation pressure, confining pressure, annular pressure, withdrawn flow rate, and thrust force, as shown in Figures 3 and 8. However, according to the control objective, there are three kinds of control subsystem:

(1) Each individual control subsystem for pressure, such as formation pressure, confining pressure, and annular pressure, mainly consists of the master controller, digital to analog converter, servo controller, synchronous motor, decelerator, ball screw, piston cylinder, load, pressure sensor, and signal processor. These three control subsystems can provide the high-precision formation pressure, confining pressure, and annular pressure to simulate the testing environment of FPTWD. The control accuracy of each pressure can reach an absolute pressure of $\pm 5.0 \mathrm{psi}$, and the measuring accuracy of these pressure sensors is \pm 1.0 psi.

(2) The individual control subsystem for the withdrawn flow rate mainly consists of the master controller, digital to analog converter, servo controller, synchronous motor, decelerator, ball screw, piston cylinder, load, pressure and displacement sensor, and signal processor, where the displacement sensor is configured to control the withdrawn flow rate of the fluid, while the pressure sensor is configured to measure the withdrawn pressure. Therefore, the withdrawn subsystem can conduct high-precision withdrawn testing, but it cannot perform the servo control of the withdrawn pressure. The withdrawn subsystem has a withdrawn volume of $0-25 \mathrm{ml}$ with a precision of $\pm 0.1 \%$, the drawdown flow rate of $0-5 \mathrm{ml} / \mathrm{s}$ with a precision of $\pm 0.1 \%$, and pressure measuring accuracy of \pm 1.0 psi.

(3) The individual control subsystem of thrust force mainly consists of the master controller, digital to analog converter, servo controller, synchronous motor, decelerator, ball screw, load, force and displacement sensor, and signal processor. The thrust force subsystem is used to simulate the process of setting packer and provide the packer sealing. Therefore, the thrust force control is very important for the thrust force subsystem. The control accuracy of thrust force can reach a relative value of $\pm 1.0 \% \mathrm{FS}$, and the thrust displacement of packer is $40-60 \mathrm{~mm}$ with a control precision of $\pm 1.0 \%$ FS.

3.5. The Physical Simulation System. Figure 9 shows the real photos of the physical simulation system. The physical environment simulator that consists of foundation, core 


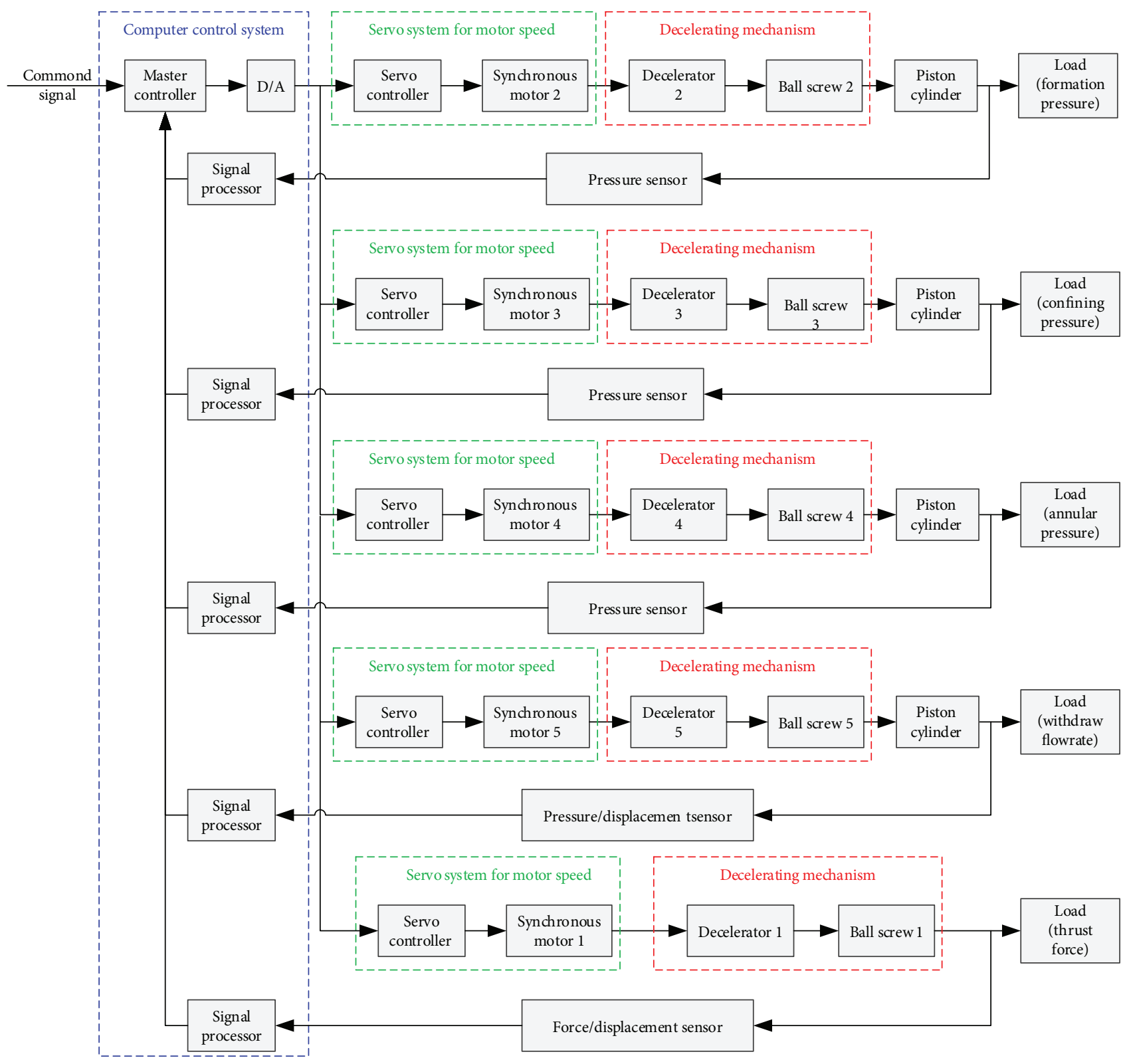

Figure 8: Scheme of the control system.

holder, packer, thrust rod, one decelerator, ball screw 1, and servomotor 1 was configured separately, due to its huge volume and weight. The withdrawn subsystem that consists of servo controller, synchronous motor 5, decelerator 5, ball screw 5, piston cylinder, pressure, and displacement sensors was also configured separately; due to this, the subsystem sometimes needs to be replaced by a real withdrawn system of FPTWD tools, as shown in Figure 9(b). The other elements were configured on the experimental platform, where the servo control subsystems were installed in the bottom of the platform, while the computer, driving and controlling system, pressure gages, valves, and vessels were installed in the top of the platform. These two parts were connected by stainless steel tubes and cables. In this way, it is beneficial to simplify experiment operation and insure experiment safety.
The main performance indicators are listed as follows: specimen diameter is $160 \mathrm{~mm}$, specimen length is 50 $200 \mathrm{~mm}$ (adjustable), confining pressure is $0-20,000 \mathrm{psi}$ with a precision of $0.02 \%$ FS, formation pressure is $0-20,000$ psi with a precision of $0.02 \% \mathrm{FS}$, annular pressure is $0-$ 20,000 psi with a precision of $0.02 \%$ FS, the control precision is \pm 1.0 psi when the pressure is stable, thrust force of the packer is $15-50 \mathrm{kN}$ with a control precision of $\pm 1.0 \% \mathrm{FS}$, thrust displacement of the packer is $40-60 \mathrm{~mm}$ with a control precision of $\pm 1.0 \% \mathrm{FS}$, withdrawn volume is $0-25 \mathrm{ml}$ with a precision of $\pm 0.1 \%$, and drawdown flow rate is $0-5 \mathrm{ml} / \mathrm{s}$ with a precision of $\pm 0.1 \%$.

3.6. Main Operating Procedures. The main workflow of the physical simulation system is as follows (as shown in Figures 3 and 9): 

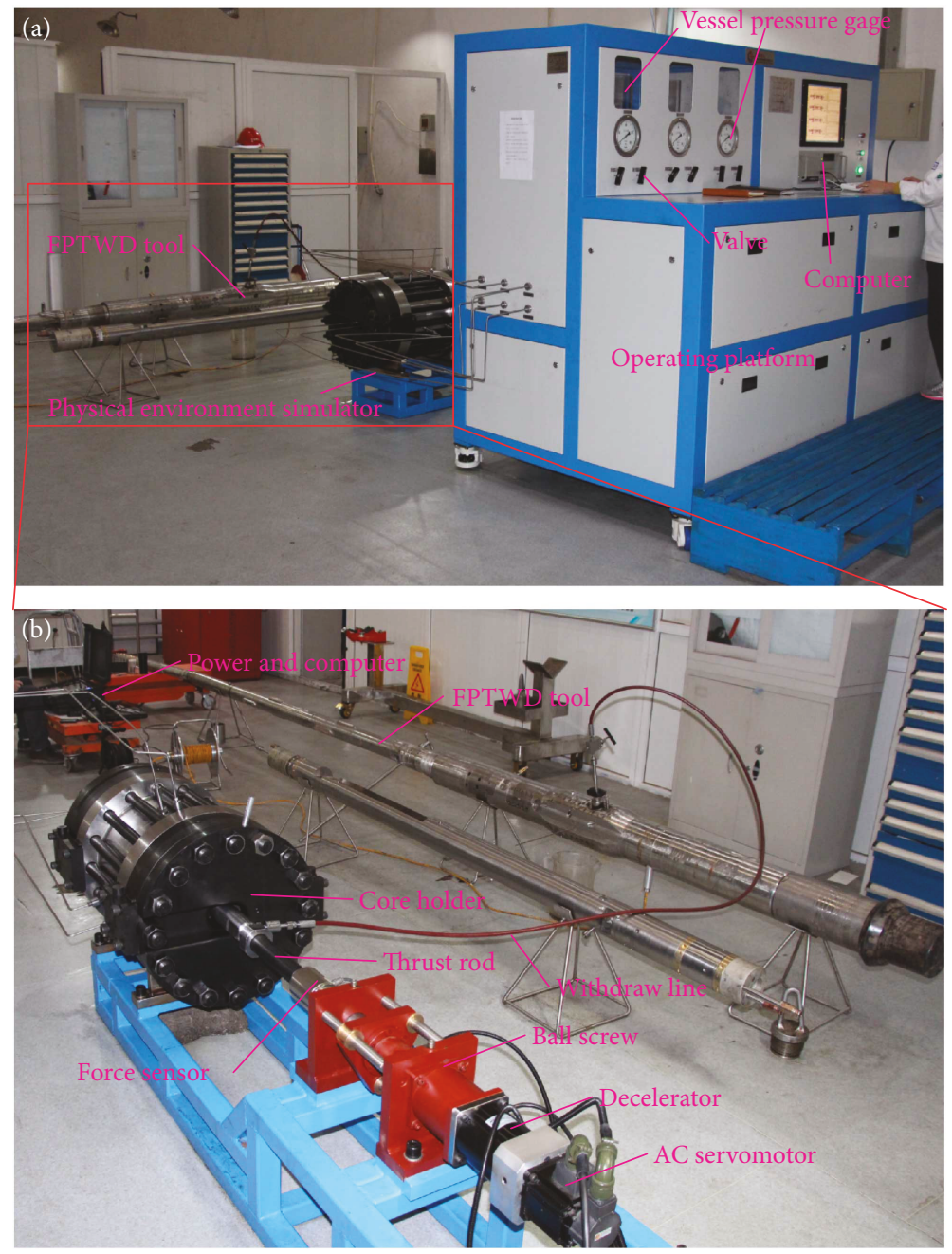

Figure 9: Photos of the physical simulation system for FPTWD. (a) The whole physical simulation system. (b) The physical environment simulator with a real withdrawn system of a FPTWD tool.

(1) Prepare for the physical simulation experiment. Install the testing sample, tighten the bolt, and connect all lines.

(2) Inject liquids to the vessels. Close valve numbers 1-3, and inject different liquids to three vessels, such as formation fluids for formation pressure, oil for confining pressure, and drilling mud for annular pressure.

(3) Inject liquids to the cylinders. Power on the physical simulation system, close valve numbers 4-6, and open valve numbers $1-3$, then control servomotor numbers $2-4$ to suction different liquids into the corresponding cylinders.

(4) Push the probe out to seal the packer. Close valve numbers $1-3$, and open valve numbers $4-6$. Firstly, start servomotor number 3 to drive the decelerator, ball screw, and piston to move onto the left to apply the confining pressure. Secondly, start servomotor numbers 2 and 4 to drive the decelerator, ball screw, and piston to move onto the left to apply the formation pressure and annular pressure independently. Note that the confining pressure should always be greater than the formation pressure and annular pressure. The confining pressure, formation pressure, and annular pressure should be automatically controlled by the computer.

(5) Start the sealing sequence for FPTWD testing. Open valve number 7; start servomotor number 1 to drive the probe setting and packer sealing on the right end of the sample, and the thrust force and displacement should be automatically controlled by the computer.

(6) Start the testing sequence of FPTWD. If the withdrawn subsystem is used, start servomotor number 5 to drive the decelerator, ball screw, and piston to move onto the right to withdraw formation fluid, where the withdrawn flow rate and volume must be automatically controlled by the computer, and pressure sensor number 5 records the response of 
TABLE 1: Main mineral composition and content.

\begin{tabular}{|c|c|c|c|c|c|c|}
\hline \multirow{2}{*}{ Number } & \multirow{2}{*}{ Lithology } & \multicolumn{5}{|c|}{ Mineral composition and content (\%) } \\
\hline & & Quartz & Orthoclase & Plagioclase & Calcite & Clay mineral \\
\hline 1 & Fine siltstone & 81.67 & 2.05 & 1.33 & 1.47 & 13.48 \\
\hline 2 & Fine siltstone & 70.85 & 1.58 & 1.20 & 1.32 & 25.05 \\
\hline \multirow[t]{4}{*}{3} & Fine siltstone & 74.64 & 2.35 & 1.50 & 1.86 & 19.65 \\
\hline & Max. & 81.67 & 2.35 & 1.50 & 1.86 & 25.05 \\
\hline & Min. & 70.85 & 1.58 & 1.20 & 1.32 & 13.48 \\
\hline & Mean & 75.72 & 1.99 & 1.34 & 1.55 & 19.39 \\
\hline 4 & Coarse siltstone & 85.83 & 0.88 & 1.00 & 0.95 & 11.34 \\
\hline 5 & Coarse siltstone & 76.80 & 1.06 & 0.90 & 0.95 & 20.30 \\
\hline \multirow[t]{4}{*}{6} & Coarse siltstone & 83.15 & 0.96 & 1.37 & 0.79 & 13.72 \\
\hline & Max. & 85.83 & 1.06 & 1.37 & 0.95 & 20.30 \\
\hline & Min. & 76.80 & 0.88 & 0.90 & 0.79 & 11.34 \\
\hline & Mean & 81.93 & 0.97 & 1.09 & 0.90 & 15.12 \\
\hline
\end{tabular}

pressure drawdown. If the withdrawn system of a real FPTWD tool is used, start the withdrawn system to withdraw formation fluid, where the withdrawn flow rate and volume must be automatically controlled by the FPTWD tool, and both pressure sensor number 5 and built-in pressure sensor can record the response of pressure drawdown.

(7) Test the response of buildup pressure for FPTWD. If the withdrawn subsystem is used, control the withdrawn subsystem to stop withdrawing formation fluid and waiting for pressure buildup; that is, stop servomotor number 5 to wait for pressure buildup in the pretest piston, and pressure sensor number 5 records the response of buildup pressure. If the withdrawn system of a real FPTWD tool is used, control the withdrawn system to stop withdrawing formation fluid, where both pressure sensor number 5 and built-in pressure sensor can record the response of pressure buildup. After pressure buildup is begging, the repeated pumping tests can be performed, and the operator just needs to repeat step (6) to step (7).

(8) End the testing sequence of FPTWD. Start servo motor numbers $2-4$ to release the confining pressure, formation pressure, and annular pressure; then start servomotor number 1 to retract the probe and unseal the packer. If the withdrawn subsystem is used, start servo motor number 5 to pump the fluid out of the pretest piston. If the withdrawn system of a real FPTWD tool is used, control the withdrawn system to pump the fluid out. After finishing the whole testing sequence, the repeated tests can be performed, and the operator just needs to repeat step (5) to step (8).

(9) Finish the testing. Close valve numbers 4-6, and separate the core holder to take the sample out. Open valve numbers $1-3$, and start servomotor numbers 2-4 to pump fluids out of the cylinders.
(10) Finally, power off the physical simulation system, and clean up the experimental platform.

\section{Verification Testing of the Physical Simulation System}

4.1. Testing Specimens. The testing samples used are two kinds of man-made siltstone. The instrument of X-ray diffraction (XRD) was adopted to determine the mineral composition for two kinds of man-made siltstone. The XRD testing results indicated that both the fine and the coarse siltstones are featured by rich in quartz, followed by clay mineral, feldspar, and calcite, and the mineral content is shown in Table 1. It is clearly found that the content of quartz in the fine siltstone is lower than that in the coarse siltstone, while the content of clay mineral in the fine siltstone is greater than that in the coarse siltstone. These two kinds of siltstone are fine grained and tawny in color. The dry density is measured as $2.50 \mathrm{~g} / \mathrm{cm}^{3}$ and $2.24 \mathrm{~g} / \mathrm{cm}^{3}$ for the fine siltstone and coarse siltstone, respectively. The scanning electron microscope (SEM) was used to observe these two kinds of siltstone. As shown in Figure 10, the grain size of the fine siltstone mainly ranges from $0.01 \mathrm{~mm}$ to $0.05 \mathrm{~mm}$, while the grain size of the coarse siltstone mainly ranges from $0.05 \mathrm{~mm}$ to $0.10 \mathrm{~mm}$. Finally, rock specimens with a size of $160 \mathrm{~mm}$ in diameter and $200 \mathrm{~mm}$ in length are sliced from the homogenous man-made block.

4.2. Testing Steps. In order to verify the present physical simulation system, a series of experiments had been conducted. The testing samples used are man-made siltstones, and the penetrating liquids are oil. The experimental study is carried out in three steps: (1) saturate the rock specimens by using the simulated formation oil; (2) test the control accuracy of the physical simulation system; and (3) conduct the physical simulation experiments based on the main operation procedures of the physical simulation system. Figure 11 shows a part of experimental specimens, where one of them was saturating by using the simulated formation oil, and a steel specimen was used to debug this physical simulation system. 


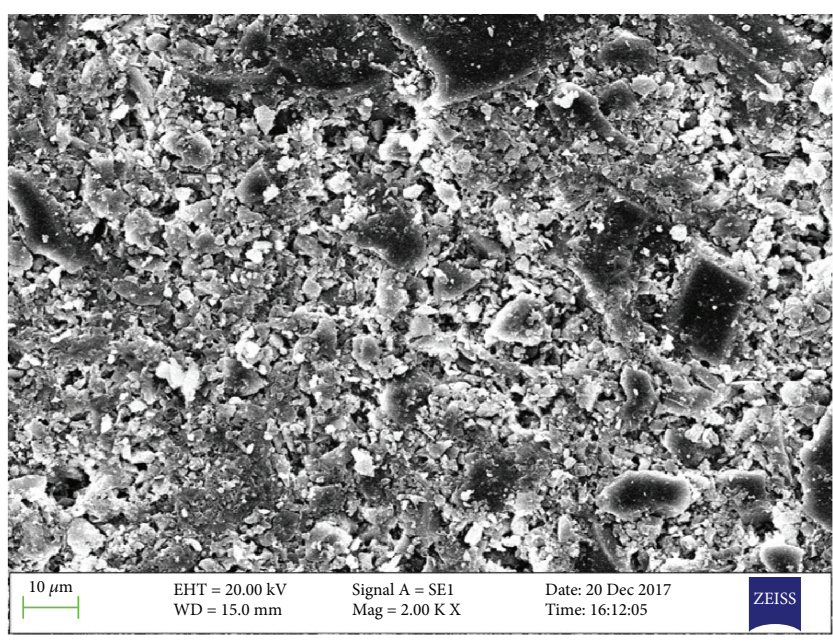

(a)

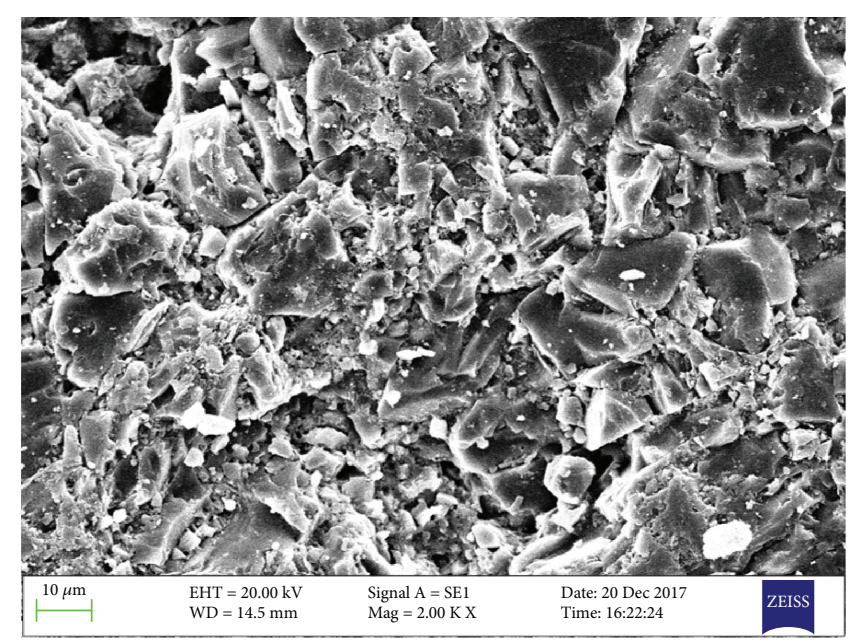

(b)

FIGURE 10: SEM images of these two man-made siltstones. (a) Fine siltstone. (b) Coarse siltstone.

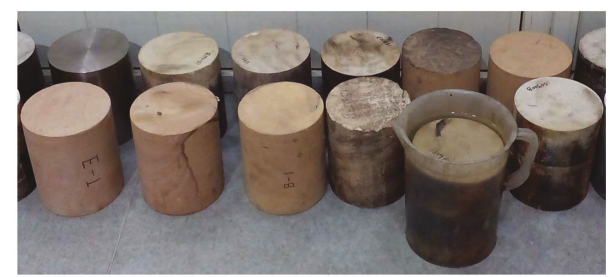

FIGURE 11: Testing specimens of physical simulation experiments.

Using this steel specimen, this physical simulation system was debugged. After debugging this physical simulation system, simulation experiments were performed with high to low permeabilities of $10-200 \mathrm{mD}$ and medium to high formation pressures of 1500-5000 psi. During testing, the suction rate was controlled as $0.5-3 \mathrm{ml} / \mathrm{s}$, the suction volume was $5-15 \mathrm{ml}$, and suction time was $3-5 \mathrm{~s}$. The thrust force was approximately $20 \mathrm{kN}$.

4.3. Debugging Results. Figure 12 shows the debugging results of annular pressure, pore pressure, confining pressure, and thrust force under a given value in 1000 seconds. It is clearly found that the variation amplitude is approximately $0.07 \mathrm{psi}$, $0.08 \mathrm{psi}, 0.11 \mathrm{psi}$, and $0.11 \mathrm{kN}$ for the annular pressure, pore pressure, confining pressure, and thrust force, respectively. The control objective is $1200 \mathrm{psi}, 1150 \mathrm{psi}, 1750 \mathrm{psi}$, and $20 \mathrm{kN}$ for the annular pressure, pore pressure, confining pressure, and thrust force, respectively. Thus, the thrust force also can meet the control accuracy of force with a value of $\pm 1.0 \%$, and all of these pressure parameters can meet the control accuracy of pressure with a value of $\pm 1.0 \mathrm{psi}$ under the stable pressure conditions. Therefore, this physical simulation system is a high-precision experimental system.

4.4. Testing Results under Different Permeabilities. After debugging this physical simulation system, a large number of experiments were conducted to verify the present physical simulation system, to verify the validity of the analytical model, to analyze pressure response recorded by FPTWD tools, and to test the capability and design of FPTWD tools. In this paper, only two representative cases were selected to verify this physical simulation system. Figure 13 shows the testing results of pressure response for two kinds of different permeabilities ( $105.2 \mathrm{mD}$ and $10.2 \mathrm{mD})$. The confining pressure was controlled as $4500 \mathrm{psi}$, and the annular pressure was controlled as $3900 \mathrm{psi}$, while formation pressure was controlled as $3000 \mathrm{psi}$. Some characteristic parameters of these tests are listed in Table 2. It is clearly found that the present physical simulation system can record the very smooth curve of pressure response for different permeabilities. The pressure drop and pressure buildup were clearly recorded. The pressure drawdown declines rapidly in the stage of withdrawing formation fluids and then recovers slowly. The lowest pressure decreases with permeability, and the pressure drop amplitude also decreases with permeability. The final buildup pressure decreases with permeability, while the pressure buildup amplitude increases with permeability. The pressure buildup time decreases with permeability. The higher the permeability is, the higher the productivity of formation fluid. Thus, the pressure buildup of high permeability situation is much faster than that of low permeability situation.

\subsection{Discussions}

4.5.1. Comparison with Testing Results of Previous System. In this paper, the previous experimental system $[3,4]$ was also used to test the pressure response of FPTWD. These experiments have a confining pressure of $4500 \mathrm{psi}$, annular pressure of $3900 \mathrm{psi}$, formation pressure of $3000 \mathrm{psi}$, and specimen size of $100 \mathrm{~mm}$ in diameter and $100 \mathrm{~mm}$ in length. The testing results of pressure response for both the present and the previous systems are shown in Figure 14. It is clearly found that the tendency of pressure change is nearly the same for both the present and the previous systems. The cross plot of these two pressures is drawn in Figure 15, the testing pressures are almost located in the ranges of $-20 \%$ to $+40 \%$, and only a few of pressures are not located in the normal range (data in the 


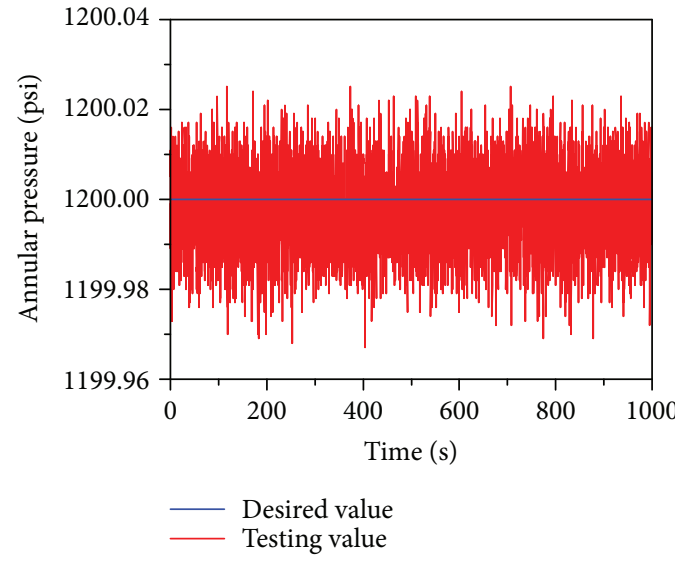

(a)

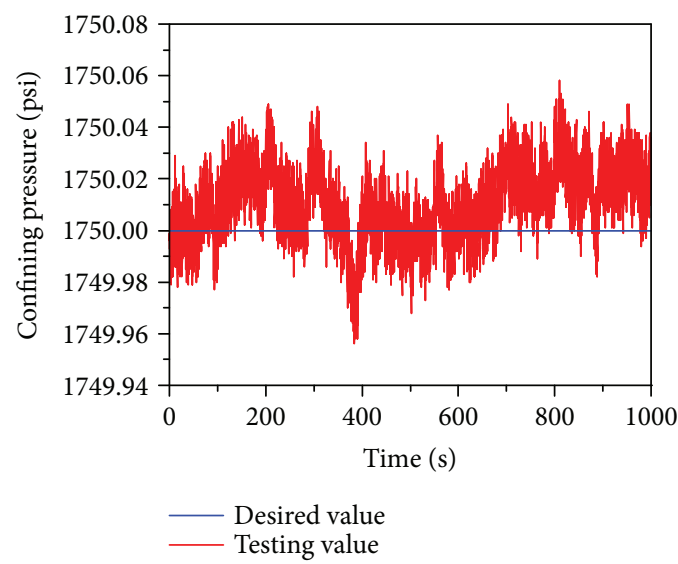

(c)

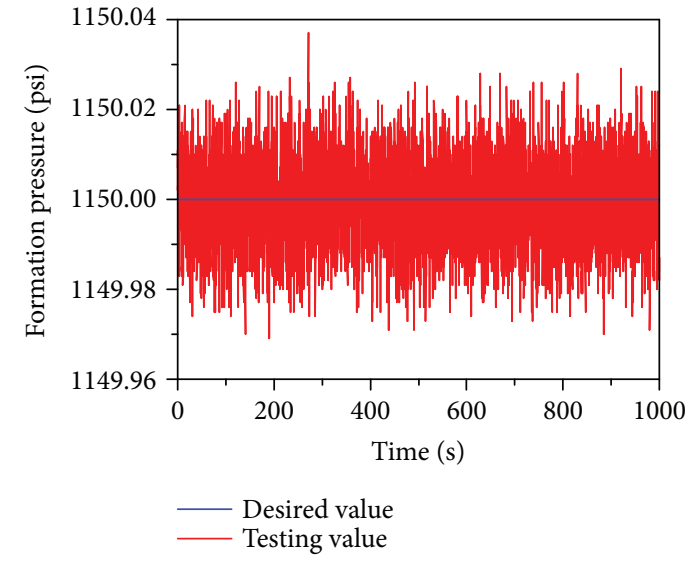

(b)

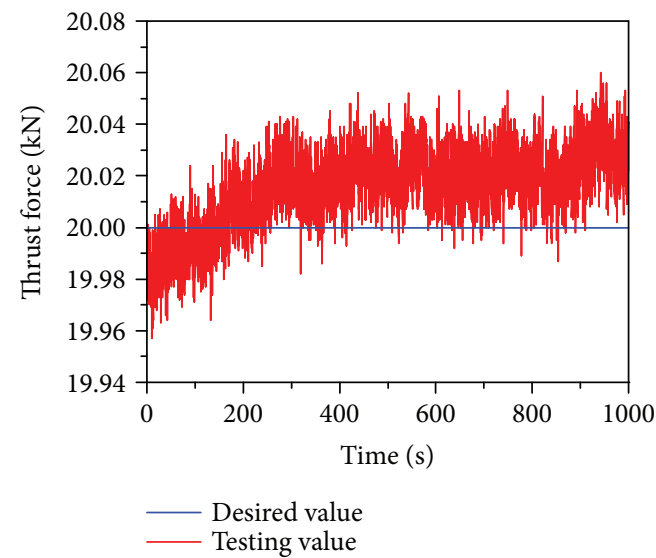

(d)

Figure 12: Debugging data of annular pressure, pore pressure, confining pressure, and thrust force under a given value in 1000 seconds. (a) Annular pressure versus time. (b) Formation pressure versus time. (c) Confining pressure versus time. (d) Thrust pressure versus time.

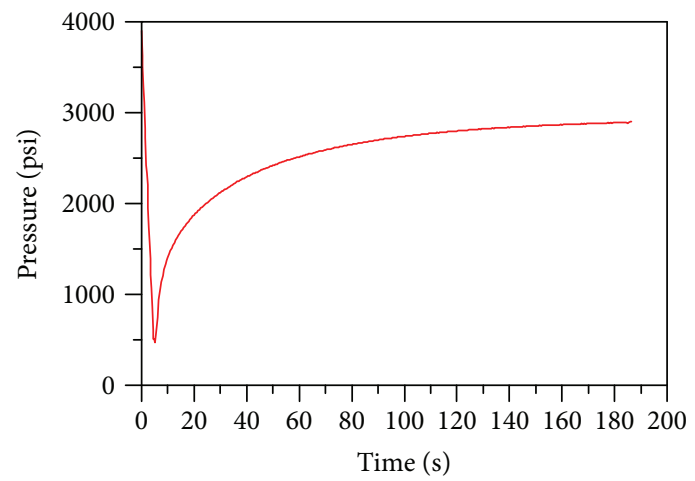

(a)

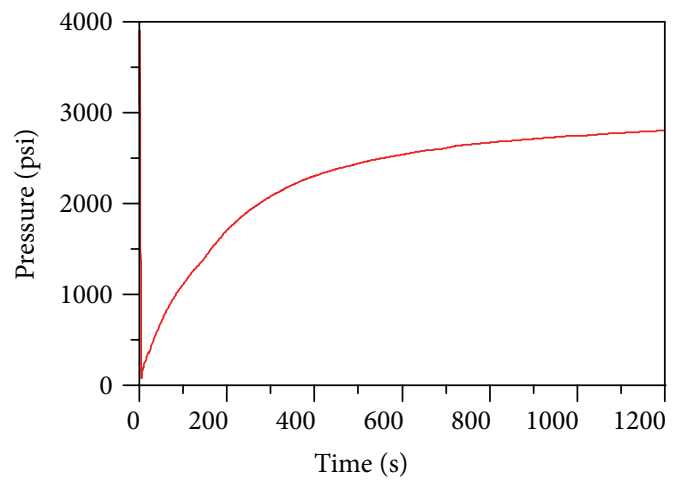

(b)

FIgURE 13: Testing results of pressure response under different permeabilities. (a) Pressure response versus time (number $1, k=105.2 \mathrm{mD}$, $q=1.5 \mathrm{ml} / \mathrm{s}, t_{0}=5 \mathrm{~s}$ ). (b) Pressure response versus time (number $2, k=10.2 \mathrm{mD}, q=0.5 \mathrm{ml} / \mathrm{s}, t_{0}=5 \mathrm{~s}$ ).

red circle of Figure 15). In fact, there also exist some significant differences in the pressure response between the present system and the previous system. On the whole, the pressure curve of the present system is smoother than that of the previous system. In the stage of pressure drop, the pressure curve of the present system is obviously higher than that of the previous system, and the pressure curve tends to linearly decline with the withdrawn time for the present system, while the pressure curve tends to unsmoothly decline with the withdrawn time for the previous system. In the stage of pressure buildup, the general trend of the pressure curve of the present system is roughly consistent with that of the previous system, and the pressure curve tends to smoothly and exponentially increase with the withdrawn time for the present system, 
TABLE 2: Experimental results.

\begin{tabular}{lccc}
\hline Number & Parameters & Number 1 & Number 2 \\
\hline 1 & Lithology & Coarse siltstone & Fine siltstone \\
2 & Permeability $(\mathrm{mD})$ & 105.2 & 10.2 \\
3 & Confining pressure $(\mathrm{psi})$ & 4500 & 4500 \\
4 & Annular pressure $(\mathrm{psi})$ & 3900 & 3900 \\
5 & Formation pressure $(\mathrm{psi})$ & 3000 & 3000 \\
6 & Pressure drop time $\left(t_{0} / \mathrm{s}\right)$ & 5.0 & 5.0 \\
7 & Withdrawn flow rate $\left(q_{0} /(\mathrm{ml} / \mathrm{s})\right)$ & 1.5 & 0.5 \\
8 & Lowest pressure $(\mathrm{psi})$ & 467 & 50 \\
9 & Pressure drop amplitude $(\mathrm{psi})$ & 3433 & 3850 \\
10 & Final buildup pressure $(\mathrm{psi})$ & 2898 & 2827 \\
11 & Pressure buildup amplitude $(\mathrm{psi})$ & 2431 & 185 \\
12 & Pressure buildup time $\left(t_{1} / \mathrm{s}\right)$ & & 2777 \\
\hline
\end{tabular}

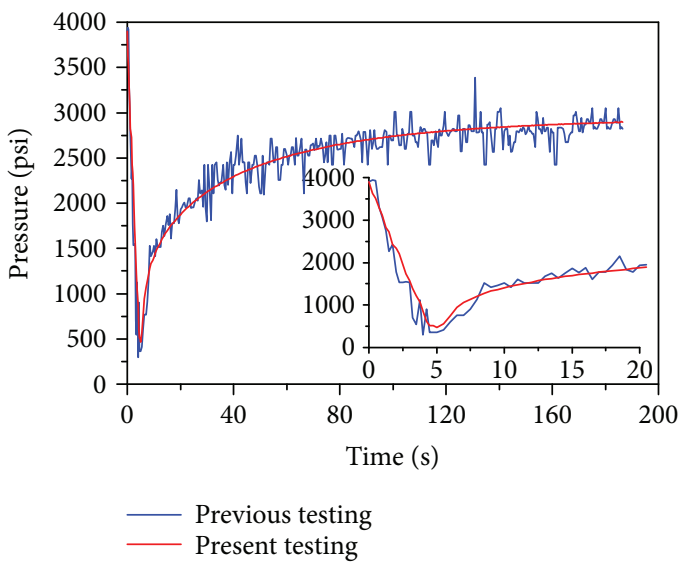

(a)

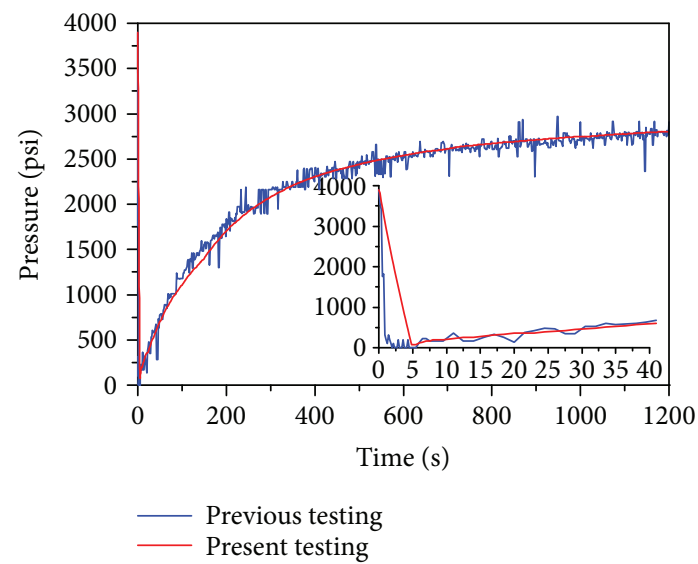

(b)

Figure 14: Testing results of pressure response for both the present and the previous systems under different permeabilities. (a) Pressure response versus time (number $1, k=105.2 \mathrm{mD}, q=1.5 \mathrm{ml} / \mathrm{s}, t_{0}=5 \mathrm{~s}$ ). (b) Pressure response versus time (number $2, k=10.2 \mathrm{mD}$, $\left.q=0.5 \mathrm{ml} / \mathrm{s}, t_{0}=5 \mathrm{~s}\right)$.

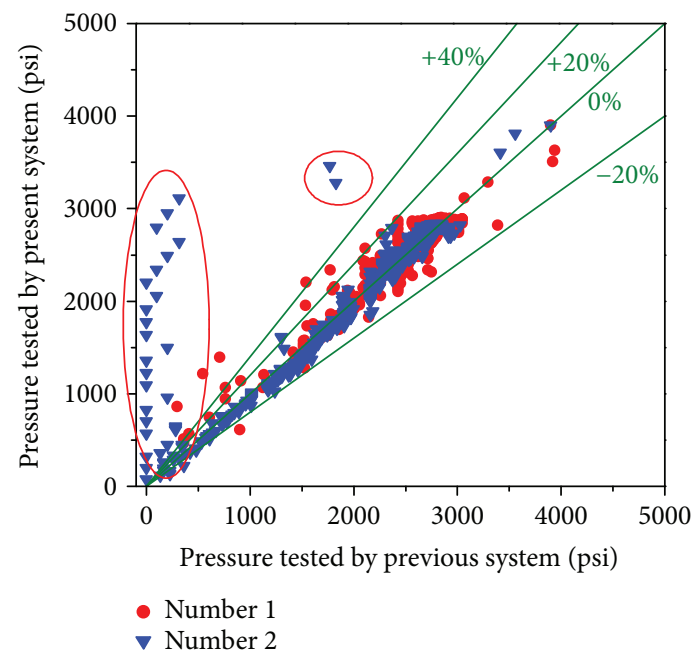

FIGURE 15: Cross-plot of two pressures for both the present and the previous systems. while the pressure curve tends to unsmoothly and exponentially increase with the withdrawn time for the previous system. For the high permeability specimen $(k=105.2 \mathrm{mD})$, the pressure response curve is very close to each other for both the present and the previous systems. However, for the low permeability specimen $(k=10.2 \mathrm{mD})$, the pressure buildup curve is very close to each other for both the present and the previous systems, while the difference of two pressure drop curves is very significant, even the previous system cannot capture the process of pressure drop. The error between these two pressures in the pressure drop stage and the initial stage of pressure buildup is much higher than that of the other stages. The error of specimen number 1 is less than $\pm 40 \%$, while the error in the middle and late stages of pressure buildup is obviously less than $\pm 20 \%$; the error of specimen number 2 is less than $\pm 60 \%$, while the error in the middle and late stages of pressure buildup is obviously less than $\pm 20 \%$. The reason is due to the difference of control accuracy for pressures. In the previous system, the control accuracy of pressures is not enough, so the pressure is not very stable, and therefore, the pressure 
TABLE 3: Explained results of formation pressure.

\begin{tabular}{lccc}
\hline Number & Parameters & Number 1 & Number 2 \\
\hline 1 & Lithology & Coarse siltstone & Fine siltstone \\
2 & Permeability $(\mathrm{mD})$ & 105.2 & 10.2 \\
3 & Confining pressure $(\mathrm{psi})$ & 4500 & 4500 \\
4 & Annular pressure $(\mathrm{psi})$ & 3900 & 3900 \\
5 & Formation pressure $(\mathrm{psi})$ & 3000 & 3000 \\
6 & Pressure drop time $\left(t_{0} / \mathrm{s}\right)$ & 5.0 & 5.0 \\
7 & Withdrawn flow rate $\left(q_{0} /(\mathrm{ml} / \mathrm{s})\right)$ & 1.5 & 0.5 \\
8 & Explained results using the present system $(\mathrm{psi})$ & 2895.12 & 2873.22 \\
9 & Absolute error $(\mathrm{psi})$ & -4.88 & -26.78 \\
10 & Relative error $(\%)$ & -0.17 & -0.92 \\
11 & Explained results using the previous system $(\mathrm{psi})$ & 2849.23 & -115.12 \\
12 & Absolute error $(\mathrm{psi})$ & -50.77 & -3.97 \\
13 & Relative error $(\%)$ & -1.75 & 2784.88 \\
\hline
\end{tabular}

response is not smooth. Thus, the present system is much better than the previous system.

4.5.2. Interpretation of Formation Parameters. The process of formation pressure testing is actually a fluid seepage process in pore spaces of porous formations. As shown in Figure 2, the most important stages are mainly the pressure drawdown stage and the pressure buildup stage, and the pressure response of these two stages can be expressed as follows [4]:

$$
\begin{aligned}
P(t)= & P_{\mathrm{i}}-\frac{q \mu G_{\mathrm{eff}}(1+S)}{2 \pi r_{\mathrm{p}} \sqrt{k_{\mathrm{fV}} k_{\mathrm{fH}}}}[1-\exp (A t)], \quad t \leq t_{0}, \\
P(t)= & P_{\mathrm{i}}-\frac{q \mu G_{\mathrm{eff}}(1+S)}{2 \pi r_{\mathrm{p}} \sqrt{k_{\mathrm{fV}} k_{\mathrm{fH}}}} \exp \\
& \cdot\left[A\left(t-t_{0}\right)\right]\left[1-\exp \left(A t_{0}\right)\right], \quad t>t_{0},
\end{aligned}
$$

where constant $A$ is given as

$$
A=-\frac{2 \pi r_{\mathrm{p}} \sqrt{k_{\mathrm{fV}} k_{\mathrm{fH}}}}{\mu C_{\mathrm{f}} V_{\mathrm{s}}(1+S)},
$$

where $S$ is the skin coefficient, $k_{\mathrm{fH}}$ is the horizontal permeability $(\mathrm{mD}), k_{\mathrm{fV}}$ is the vertical permeability $(\mathrm{mD}), G_{\mathrm{eff}}$ is the pressure correction factor, $t_{0}$ is the withdrawn time $(\mathrm{s})$, $C_{\mathrm{f}}$ is the fluid compressibility (1/psi), and $V_{\mathrm{s}}$ is the flowline volume (cc).

By using (11) and (12), the explained formation pressure is listed in Table 3. It is clearly found that the explained formation pressure of the present system is obviously much better than that of the previous system. Using the previous system, the absolute error is approximately $-50.77 \mathrm{psi}$ and -115.12 psi for specimen number 1 and number 2, respectively. While using the present system, the absolute error is approximately $-4.88 \mathrm{psi}$ and $-26.78 \mathrm{psi}$ for specimen number 1 and number 2, respectively. In other words, the absolute error is less than 30 psi and 120 psi for the present and the previous systems, respectively. Using the previous system, the relative error is approximately $-1.75 \%$ and $-3.97 \%$ for specimen number 1 and number 2 , respectively. While using the present system, the absolute error is approximately $-0.17 \%$ and $0.92 \%$ for specimen number 1 and number 2 , respectively. In other words, the relative error is less than $1 \%$ and $4 \%$ for the present and the previous systems, respectively. In addition, the error under high permeability condition is obviously lower than that of low permeability condition. On the whole, the present can meet the requirements of formation pressure calibration.

\section{Concluding Remarks}

In the present paper, all of the determination methods of formation pressure and their features were reviewed, including the predrill pore pressure prediction, the pore pressure detection during drilling, the postdrill pore pressure prediction or detection (well logging method, drill stem test (DST), wireline formation test (WFT)), and the formation pressure testing while drilling (FPTWD). The major principle of FPTWD and existing physical simulation systems for FPTWD was introduced, and the deficiency of the existing physical simulation systems was also discussed.

A laboratory scale high-precision physical simulation system was designed and developed to simulate the downhole testing environment and testing process of FPTWD tools. The key parts of this physical simulation system, such as the sample size, core holder, control system, and main operating procedures, had been introduced. Compared to the previous physical simulation systems, the experimental system was designed to endure pressures up to 20,000 psi. The debugging test results indicated that the variation amplitude under the stable condition is approximately $0.07 \mathrm{psi}, 0.08 \mathrm{psi}, 0.11 \mathrm{psi}$, and $0.11 \mathrm{kN}$ for the annular pressure, pore pressure, confining pressure, and thrust force, respectively. Thus, the control accuracy of pressure can reach approximately \pm 1.0 psi under the stable conditions, and the thrust force also can meet the control accuracy of force with a value of $\pm 1.0 \%$.

A large number of physical simulation experiments were conducted to verify the present physical simulation system. There are two kinds of different specimens with the 
permeability of $10-110 \mathrm{mD}$ which were used to test the pressure response of FPTWD. The results indicated that the pressure drawdown declines rapidly in the stage of withdrawing formation fluids and then recovers slowly. The present system can record a very smooth curve of pressure response for different permeabilities.

The lowest pressure decreases with permeability, and the pressure drop amplitude also decreases with permeability. The final buildup pressure decreases with permeability, while the pressure buildup amplitude increases with permeability. The pressure buildup time increases with permeability. The tendency of pressure change is nearly the same for both the present and the previous systems; the pressure curve of the present system is smoother than that of the previous system. The absolute error is less than $30 \mathrm{psi}$ and 120 psi for the present and the previous systems, respectively, and the relative error is less than $1 \%$ and $4 \%$ for the present and the previous systems, respectively. The error under high permeability condition is obviously lower than that of low permeability condition.

In the present paper, only two kinds of typical cases were introduced. Due to the capacity of high precision and high pressure, this physical simulation system has important applications. In the future, more physical experiments should be conducted to further inspect and verify the design of the present system and to apply it to verify the validity of the analytical model, to analyze pressure response recorded by FPTWD tools, to test the capability and design of FPTWD tools, and to calibrate the formation pressure, formation fluidity, fluid compression coefficient, and instrument factors.

\section{Data Availability}

All data are provided in full in the testing result section of this article.

\section{Conflicts of Interest}

The authors declare that there are no conflicts of interest regarding the publication of this paper.

\section{Acknowledgments}

This work was supported by the Young Elite Scientists Sponsorship Program by China Association for Science and Technology (Grant no. 2017QNRC001), the National Natural Science Foundation of China (Grant no. 51604230), the China Postdoctoral Science Foundation (Grant nos. 2016M600626 and 2017T100592), and the Scientific Research Foundation of International Cooperation and Exchanges of Sichuan Province (Grant no. 2016HH0001).

\section{References}

[1] C. M. Sayers, G. M. Johnson, and G. Denyer, "Predrill porepressure prediction using seismic data," Geophysics, vol. 67, no. 4, pp. 1286-1292, 2002.

[2] M. R. P. Tingay, R. R. Hillis, R. E. Swarbrick, C. K. Morley, and A. R. Damit, "Origin of overpressure and pore-pressure prediction in the Baram province, Brunei," AAPG Bulletin, vol. 93, no. 1, pp. 51-74, 2009.

[3] T. S. Ma and P. Chen, "Mathematical model and physical experimental research for pressure response of formation testing while drilling," Chinese Journal of Geophysics, vol. 57, no. 7, pp. 2321-2333, 2014.

[4] T. Ma, P. Chen, and X. Han, "Simulation and interpretation of the pressure response for formation testing while drilling," Journal of Natural Gas Science and Engineering, vol. 23, pp. 259-271, 2015.

[5] J. Zhang, "Pore pressure prediction from well logs: methods, modifications, and new approaches," Earth-Science Reviews, vol. 108, no. 1-2, pp. 50-63, 2011.

[6] J. Zhang and S. Yin, "Real-time pore pressure detection: indicators and improved methods," Geofluids, vol. 2017, Article ID 3179617, 12 pages, 2017.

[7] T. Ma, B. Wu, J. Fu, Q. Zhang, and P. Chen, "Fracture pressure prediction for layered formations with anisotropic rock strengths," Journal of Natural Gas Science and Engineering, vol. 38, pp. 485-503, 2017.

[8] T. Ma, Q. B. Zhang, P. Chen, C. Yang, and J. Zhao, "Fracture pressure model for inclined wells in layered formations with anisotropic rock strengths," Journal of Petroleum Science and Engineering, vol. 149, pp. 393-408, 2017.

[9] T. Ma, N. Peng, Z. Zhu, Q. Zhang, C. Yang, and J. Zhao, "Brazilian tensile strength of anisotropic rocks: review and new insights," Energies, vol. 11, no. 2, p. 304, 2018.

[10] Z. Li, M. Dong, S. Li, and S. Huang, " $\mathrm{CO}_{2}$ sequestration in depleted oil and gas reservoirs-caprock characterization and storage capacity," Energy Conversion and Management, vol. 47, no. 11-12, pp. 1372-1382, 2006.

[11] T. Ma, P. Chen, C. Yang, and J. Zhao, "Wellbore stability analysis and well path optimization based on the breakout width model and Mogi-Coulomb criterion," Journal of Petroleum Science and Engineering, vol. 135, pp. 678-701, 2015.

[12] G. Holm, "How abnormal pressures affect hydrocarbon exploration, exploitation," Oil and Gas Journal, vol. 96, pp. 79-84, 1998.

[13] P. Segall and S. D. Fitzgerald, "A note on induced stress changes in hydrocarbon and geothermal reservoirs," Tectonophysics, vol. 289, no. 1-3, pp. 117-128, 1998.

[14] Y. Zhao, Z. Feng, B. Xi, Z. Wan, D. Yang, and W. Liang, "Deformation and instability failure of borehole at high temperature and high pressure in hot dry rock exploitation," Renewable Energy, vol. 77, pp. 159-165, 2015.

[15] C. F. Tsang, F. Bernier, and C. Davies, "Geohydromechanical processes in the excavation damaged zone in crystalline rock, rock salt, and indurated and plastic clays-in the context of radioactive waste disposal," International Journal of Rock Mechanics and Mining Sciences, vol. 42, no. 1, pp. 109-125, 2005.

[16] M. Ferronato, G. Gambolati, C. Janna, and P. Teatini, "Geomechanical issues of anthropogenic $\mathrm{CO}_{2}$ sequestration in exploited gas fields," Energy Conversion and Management, vol. 51, no. 10, pp. 1918-1928, 2010.

[17] C. E. Hottmann and R. K. Johnson, "Estimation of formation pressures from log-derived shale properties," Journal of Petroleum Technology, vol. 17, no. 6, pp. 717-722, 1965.

[18] H. Fan, "Discussion on the traditional pore pressure evaluation methods by using well logging," Petroleum Exploration and Development, vol. 30, no. 4, pp. 72-74, 2003. 
[19] B. A. Eaton, "The effect of overburden stress on geopressure prediction from well logs," Journal of Petroleum Technology, vol. 24, no. 8, pp. 929-934, 1972.

[20] B. A. Eaton, "The equation for geopressure prediction from well logs," in Proceedings of Fall Meeting of the Society of Petroleum Engineers of AIME, Dallas, Texas, USA, 1975.

[21] Y. Jin, L. Shujie, S. Lei, Z. Jian-liang, W. Ping-shuang, and Y. Xue-chang, "Research on prediction model for formation pressure in compression structure," Acta Petrolei Sinica, vol. 30, no. 5, pp. 764-768, 2009.

[22] G. L. Bowers, "Pore pressure estimation from velocity data:accounting for overpressure mechanisms besides undercompaction," SPE Drilling \& Completion, vol. 10, no. 2, pp. 89-95, 1995.

[23] N. C. Dutta, "Geopressure prediction using seismic data:current status and the road ahead," Geophysics, vol. 67, no. 6, pp. 2012-2041, 2002.

[24] J. Zhang, "Effective stress, porosity, velocity and abnormal pore pressure prediction accounting for compaction disequilibrium and unloading," Marine and Petroleum Geology, vol. 45, pp. 2-11, 2013.

[25] D. Eberhart-Phillips, D. H. Han, and M. D. Zoback, "Empirical relationships among seismic velocity, effective pressure, porosity, and clay content in -sandstone," Geophysics, vol. 54, no. 1, pp. 82-89, 1989.

[26] Z. Wang and R. Wang, "Pore pressure prediction using geophysical methods in carbonate reservoirs: current status, challenges and way ahead," Journal of Natural Gas Science and Engineering, vol. 27, no. 2, pp. 986-993, 2015.

[27] T. Cervantes, G. Bravo, J. R. Loaiza, and P. Ruiz, "Drill stem test design optimization improves quality of reservoir data and time requirements for deep and ultra deep water well testing," in Offshore Technology Conference, Houston, Texas, USA, 2012.

[28] H. Du, Y. Liu, X. Li, F. Guan, and X. Sui, "Interpreting reservoir permeabilities from wireline formation test data," Petroleum Science and Technology, vol. 31, no. 18, pp. 18191826, 2013.

[29] T. F. Shazly and A. Z. Nouh, "Determination of some reservoir characteristics of the Bahariya Formation in Bed-1 Field, Western Desert, Egypt, by using the repeat formation tester," Petroleum Science and Technology, vol. 31, no. 7, pp. 763774, 2013.

[30] M. Hooper, C. MacDonald, R. Shalhope, and P. Boonen, "Applications for an LWD formation tester," in SPE/IADC Drilling Conference, Amsterdam, Netherlands, March 1999.

[31] M. A. Proett, D. J. Seifert, W. C. Chin, S. Lysen, and P. Sands, "Formation testing in the dynamic drilling environment," in SPWLA 45th Annual Logging Symposium, Noordwijk, Netherlands, 2004.

[32] M. Proett, M. Walker, D. Welshans, and C. Gray, "Formation testing while drilling, a new era in formation testing," in Proceedings of SPE Annual Technical Conference and Exhibition, Denver, Colorado, USA, October 2003.

[33] D. Di, G. Tao, T. Zhang, Z. Wang, and X. Chen, "On real time data processing method of formation tester while drilling (geotap)," Well Logging Technology, vol. 39, no. 5, pp. 555-560, 2015.

[34] C. Zhang, S. Liu, and Y. Li, "A discussion on methods to determine reservoir mobility and productivity by using wireline formation test data," China Offshore Oil and Gas, vol. 25, no. 1, pp. 43-45, 2013.
[35] Y. Chuan, C. Ping, X. Hongquan, H. Xiong, and M. Tianshou, "Progress in research and development of measurement while drilling apparatuses," Natural Gas Industry, vol. 33, no. 2, pp. 71-75, 2013.

[36] Z. Zhao, Y. Han, J. Yang, C. Yu, M. Jiang, and H. Wang, "The study and application of SDC-I formation pressure and temperature tester while drilling," in IADC/SPE Asia Pacific Drilling Technology Conference and Exhibition, Tianjin, China, 2012.

[37] J. Zheng, D. Qian, L. Wang, Y. Zong, and Q. Wang, "Research and development of prototypes for MWD of formation pressures," Special Oil and Gas Reservoirs, vol. 24, no. 2, pp. 170-174, 2017.

[38] R. Desbrandes and H. Xu, "A new concept in wireline formation testing: extended drawdown," The Log Analyst, vol. 35, no. 6, pp. 37-46, 1994.

[39] T. S. Ramakrishnan, Y. Dave, and A. Cappiello, “A laboratory investigation of permeability in hemispherical flow with application to formation testers," SPE Formation Evaluation, vol. 10, no. 2, pp. 99-108, 1995.

[40] H. Lee, M. Proett, P. Weintraub, J. Fogal, and C. TorresVerdln, "Results of laboratory experiments to simulate the downhole environment of formation testing while drilling," in SPWLA 45th Annual Logging Symposium, Noordwijk, Netherlands, June 2004. 

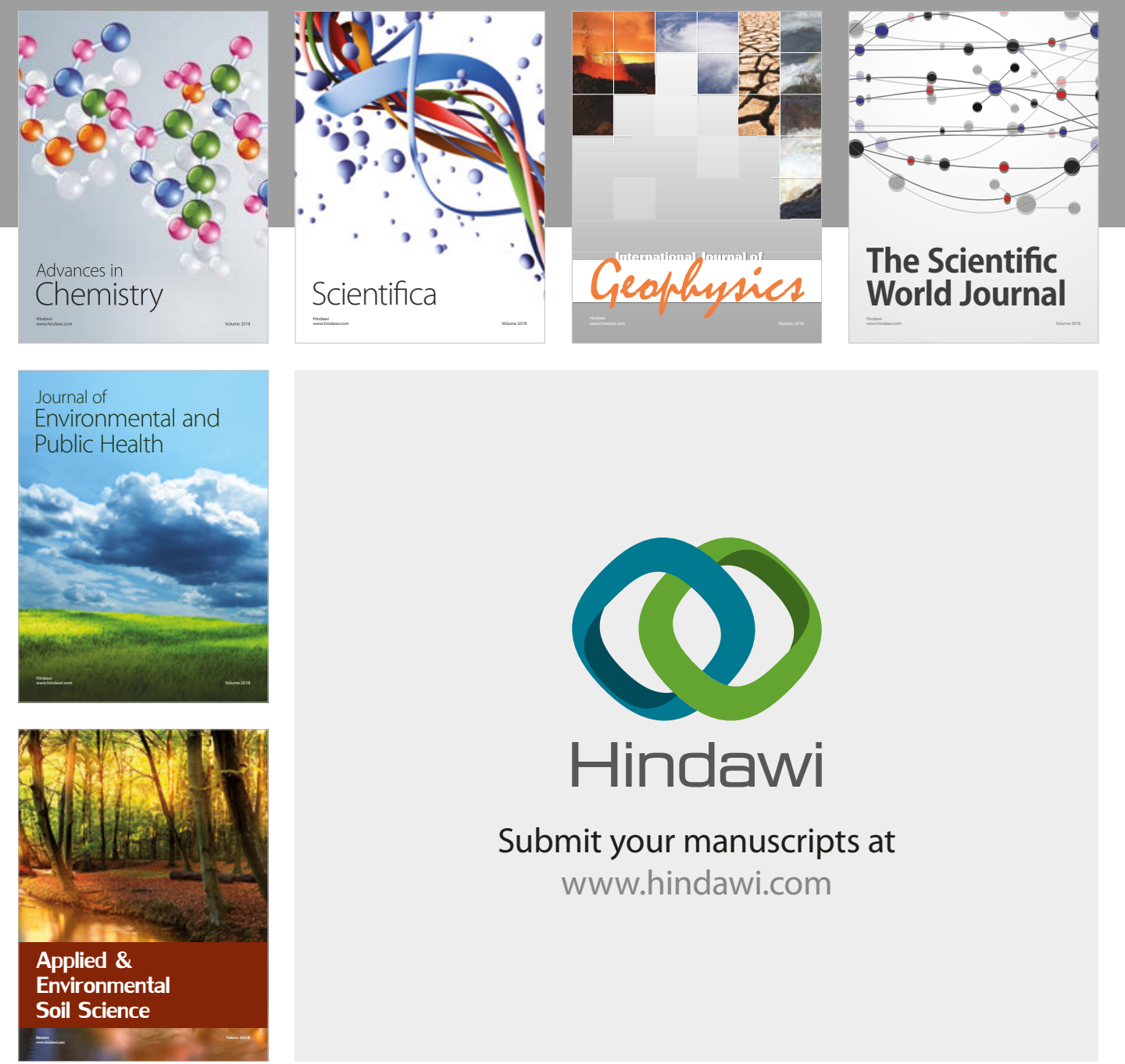

The Scientific

\section{World Journal}
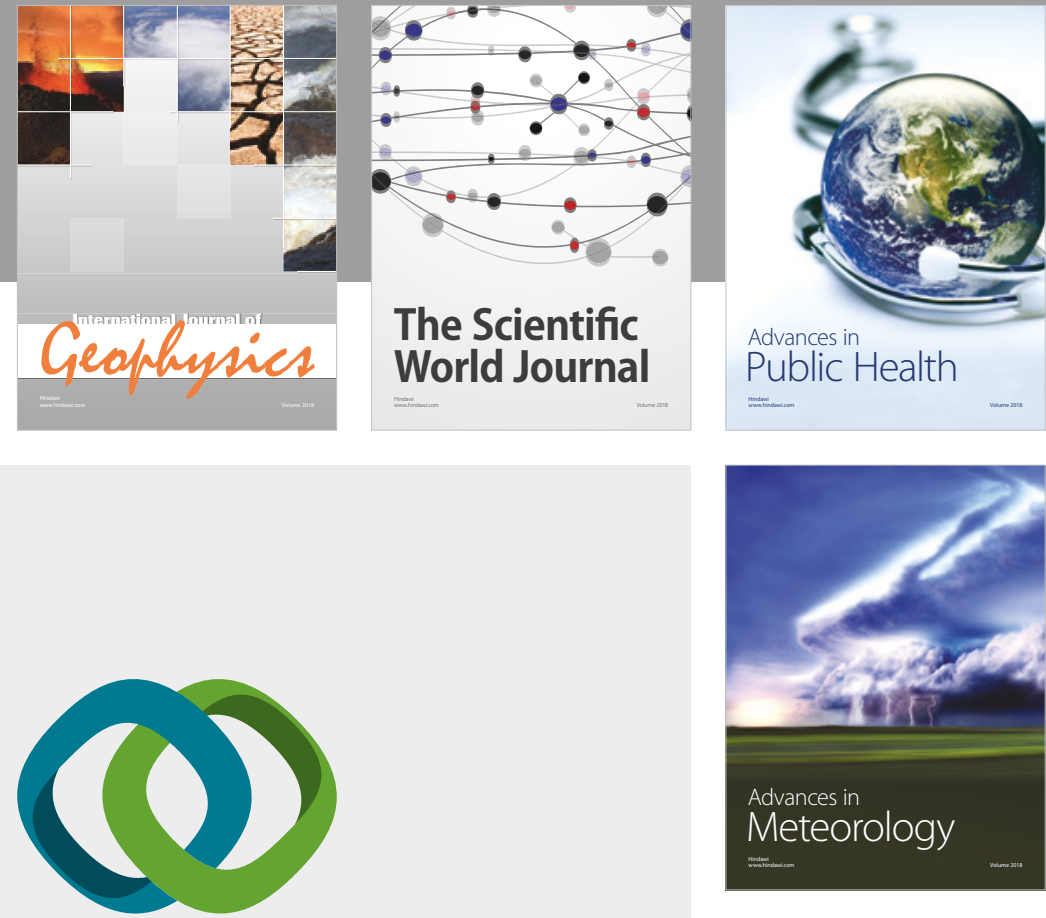

Advan

Public Health

\section{Hindawi}

Submit your manuscripts at

www.hindawi.com
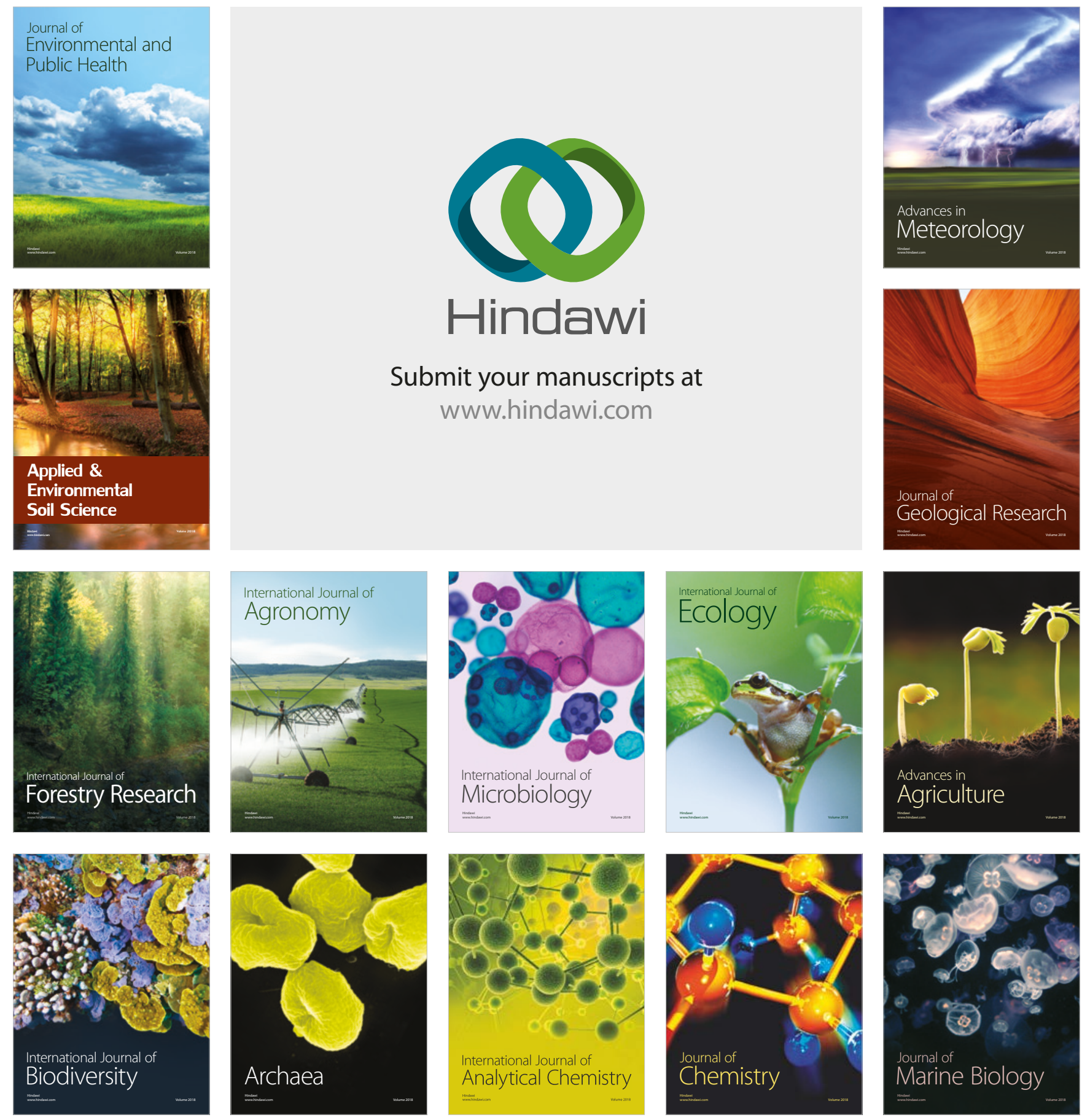